Portland State University

PDXScholar

Fall 12-7-2017

\title{
Sleep and Young Children's Development of Self- Regulation and Academic Skills
}

Emily Michelle Weiss

Portland State University

Follow this and additional works at: https://pdxscholar.library.pdx.edu/open_access_etds

Part of the Developmental Psychology Commons

Let us know how access to this document benefits you.

\section{Recommended Citation}

Weiss, Emily Michelle, "Sleep and Young Children's Development of Self-Regulation and Academic Skills" (2017). Dissertations and Theses. Paper 4081.

https://doi.org/10.15760/etd.5965

This Thesis is brought to you for free and open access. It has been accepted for inclusion in Dissertations and Theses by an authorized administrator of PDXScholar. Please contact us if we can make this document more accessible: pdxscholar@pdx.edu. 
Sleep and Young Children's Development of Self-Regulation and Academic Skills

by

Emily Michelle Weiss

A thesis submitted in partial fulfillment of the requirements for the degree of

\author{
Master of Science \\ in \\ Psychology
}

Thesis Committee:

Andrew Mashburn, Chair

Ellen Skinner

Bill Griesar

Portland State University

2017 


\begin{abstract}
School readiness incorporates children's academic abilities and their ability to self-regulate in the classroom. Prior research shows that sleep is related to children's development of these skills, although the mechanisms through which sleep affects school readiness are not well understood. Research also indicates that economically disadvantaged children and children of color may have poorer academic and regulatory skills at school entry and may sleep less and sleep less well on a regular basis.

The current study explores the role of sleep quantity and quality in young children's development of two skills critical for school success: self-regulation and academic abilities. This study intentionally focuses on a predominantly AfricanAmerican, economically disadvantaged population, who may be at risk for greater sleeprelated difficulties and lower school-related skills at kindergarten entry. It was hypothesized that a) young children with higher quantity and quality of sleep would show greater development of academic skills and self-regulation across one calendar year, b) the role of sleep in the development of these abilities would be relatively stronger among kindergarteners than among $1^{\text {st }}$ graders, and c) the role of sleep quality and quantity in young children's development of academic abilities would be partially explained by the relation between sleep and self-regulation. Results provide mixed support for the hypotheses, indicating that sleep quality and quantity relate differentially to different school-related skills among kindergarteners and $1^{\text {st }}$ graders. This study contributes research to help explain how and why sleep affects young children and may offer insights for caregivers and educators working to help children develop school-related skills.
\end{abstract}




\section{Acknowledgements}

This proposal would not have come together without the incredible support of the people in my life. I sincerely thank my lab-mates, cohort-mates, and Developmental track-mates who have given me their advice, support, and encouragement at every step of the way.

I would like to formally thank my committee for their willingness to advise on this project and especially my advisor for helping me dive in to this fascinating topic. Thanks also to the WINGS research team, on whose tremendous efforts this work is based.

And finally, to my family and my partner, thank you for all the things, all the time. I wouldn't be here without you. 


\section{Table of Contents}

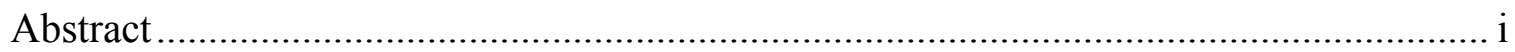

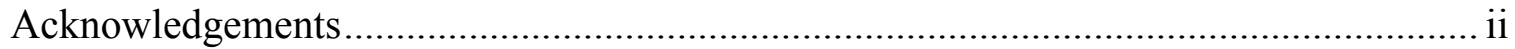

List of Figures ................................................................................................... iv

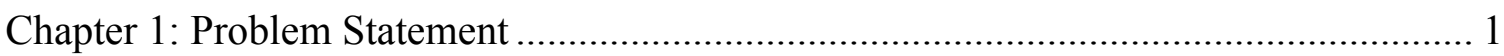

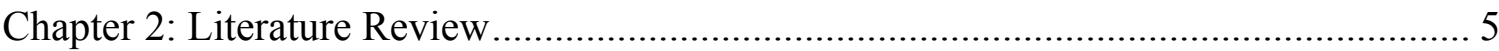

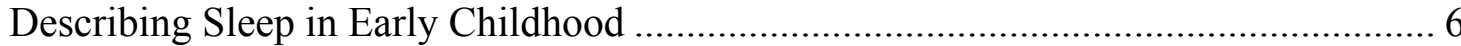

Sleep and School Success: Context and Research................................................ 13

Research Review: Sleep and School Success. ..................................................... 15

Theoretical Connections: Sleep, Self-Regulation and Academics ................................ 21

Chapter 3: Current Study .......................................................................................... 27

Research Questions and Hypotheses .................................................................... 28

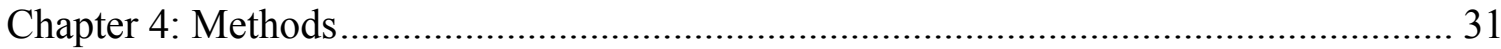

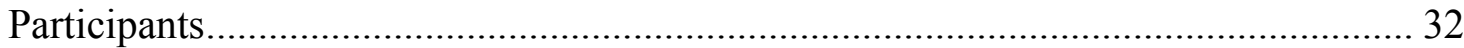

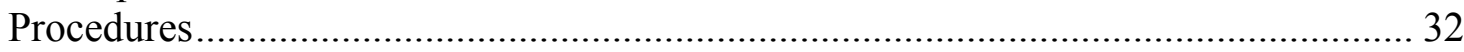

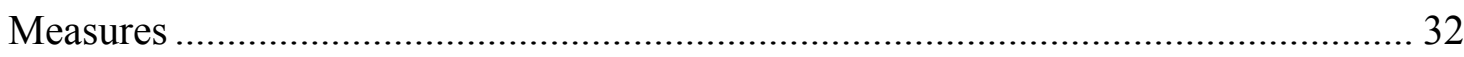

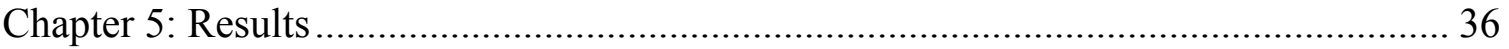

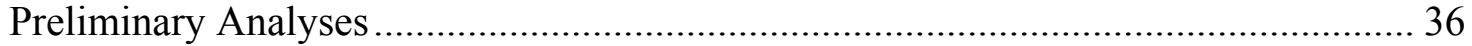

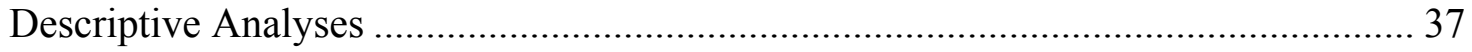

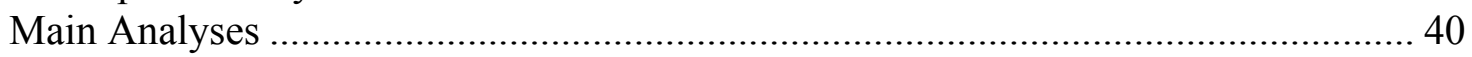

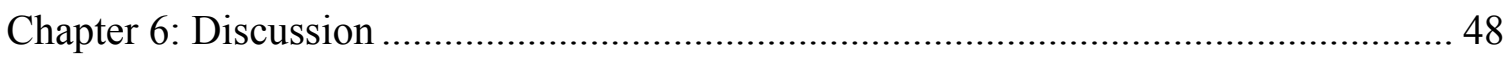

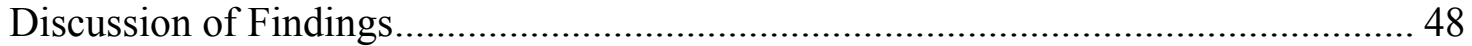

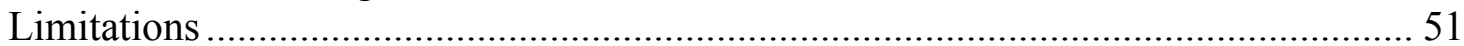

Implications for Research and Practice ………………………………………….... 55

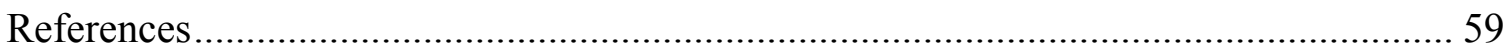

Appendix A: Summary of Key Articles …………………................................... 72

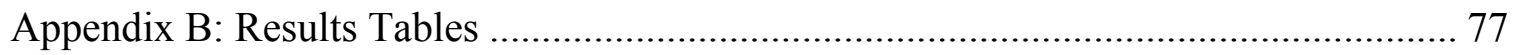




\section{List of Figures}

Figure 1. Model and Research Questions..................................... 35

Figure 2. The relation between sleep latency and self-regulation scores at Time 2, for

kindergarteners and $1^{\text {st }}$ graders.......................................... 49 


\section{Chapter 1: Problem Statement}

In the first years of school, children are asked to learn new academic material while managing their thoughts, feelings, and actions in the classroom setting. A child's capacity to meet these challenges reflects his or her school readiness, a multifaceted construct that incorporates the cognitive, emotional, behavioral and social skills young children demonstrate at school entry (NAEYC, 2009). Being ready for school is important for a child's later success (Duncan et al., 2007; Sabol \& Pianta, 2012), but as the academic demands of school get pushed earlier and earlier, children have less time in which to develop the skills they need (Bassok, Latham \& Rorem, 2016). Therefore, understanding the biological processes that underlie children's development of these skills is critical.

In order to exhibit the skills associated with school readiness, children must have a network of robust cognitive processes that dynamically regulate attention, emotion, and behavior. Dramatic growth in the pre-frontal cortex, the neural location of many higher order cognitive processes, is evident around age 5, the same time when American children transition into the school system (Dahl, 1996a; Blair, 2002). In the neurobiological model of school readiness, burgeoning neurological networks emerge as a child grows, and these networks become tailored to school-related skills when relevant experiences are offered by the environment (Blair, 2002). Therefore, children whose environments do not actively facilitate this kind of skill development, as is often the case for children in poverty, may be at comparatively greater risk of early school difficulties. 
In general, poverty is one of the most prominent risk factors for developing children. The ecology of economic disadvantage is complex, and the interplay of familial instability and chaos, neighborhood disadvantage, limited access to resources, and environmental toxins forms a cumulative network of risk factors that can have serious, detrimental effects (Ackerman \& Brown, 2011; Evans \& Kim, 2013). Children who grow up in poverty perform worse on average in school, and achievement disparities are measurable as early as kindergarten (Reardon, 2011). Moreover, evidence shows that children from low-income families tend to be less ready for school (Ryan, Fauth \& Brooks-Gunn, 2006). Disadvantaged children are less likely to attend a high-quality preschool program (Magnuson, Meyers, Ruhm \& Waldfogel, 2004), and are less likely to experience cognitive enrichment (e.g. literary activities) at home (Evans, 2004).

In recent years, researchers have looked inside the 'black box' of the brain to find more answers about the physiological effects of poverty. Studies show that poor children chronically exposed to stressors experience greater dysregulation of the stress response (Evans \& Kim, 2013) and higher cortisol levels as early as 7 months old (Blair, Raver, Granger, Mills-Koonce \& Hibel, 2011). Moreover, early exposure to poverty can have enduring effects on development that result in neurochemical differences later in life (Evans \& Kim, 2013). In the context of such cumulative patterns of risk, sleep may be an important factor in the disadvantages faced by poor children entering school.

Fundamentally, sleep is a biological process that has important psychological implications. Research suggests that sleep is critical for young children and is related to healthy development of neural architecture and adaptive stress responses (Dahl, 1996b). 
More specifically, sleep may underpin the development of essential cognitive abilities needed for school (Buckhalt \& Staton, 2011). Sleep quality and quantity are associated with a number of school-related outcomes, including academic achievement and cognitive functioning, as well as emotional and behavioral self-regulation and selfmanagement in the classroom (Astill, Van der Heijden, Van IJzendoorn \& Van Someren, 2012; Yokomaku et al., 2008). Sleep behaviors also lie at the intersection of biology and environment, which is evident in demographic and cultural differences (Owens, 2004). Research suggests that children from African-American families have different day-night sleep patterns than European-American children (Crosby, LeBourgeois \& Harsh, 2005) and that children in poverty often suffer from lower quality sleep (Grandner, Petrov, Rattanaumpawan, Jackson, Platt \& Patel, 2013; Ackerman \& Brown, 2011). Given the interplay of context and physiology, poor children may be doubly disadvantaged: they are less likely to have experiences that prepare them for school, and they are less likely to get the sleep needed to build academic and regulatory skills.

In light of this evidence, sleep may be a critical leverage point for explaining, and hopefully optimizing, children's development across the first few years of school. The current study examines the role of sleep quality and quantity in young children's development of two critical components of school success: self-regulation and academic competencies. This study intentionally focuses on economically disadvantaged children of color, who the literature shows may be at greater risk for sleep related difficulties. By looking at variations within this population, this study attempts to isolate relations 
between sleep and academics and, in doing so, hold constant other factors associated with race and income.

The following chapter, Chapter Two, describes sleep during early childhood, reviews literature on sleep and its relation to children's school success, and details theories that link sleep, self-regulation, and academic performance for young children. Chapter Three presents the current study, including research questions and hypotheses, proposing that a) young, economically disadvantaged, African-American children who experience higher quality and quantity of sleep will demonstrate greater development of academic skills and self-regulation across one calendar year, b) these positive relations will be relatively greater for kindergarteners than first graders, and c) the positive relation between children's quantity and quality of sleep and their development of academic skills will be explained, in part, by their development of self-regulation. Chapter Four outlines the methods, including information about the participants and measures. Chapter Five describes the analyses and results, and Chapter Six concludes with a discussion of findings, limitations, and implications of the research. 


\section{Chapter 2: Literature Review}

In the milieu of early childhood, many interconnected factors contribute to young children's adaptive development. Research demonstrates that sleep is one such factor, a biological necessity that is critical for the waking brain. The manifold risks associated with insufficient sleep may be amplified by environmental factors (e.g. poverty) or demographic characteristics (e.g. race, culture). This dynamic may be even more sensitive during the critical period of entry into the school system. Taken together, these features necessitate a thorough exploration of sleep and the developing child in the context of school and social address.

The following chapter reviews central constructs, theories, and empirical research related to sleep in early childhood to provide background and context for the proposed study. First, sleep will be described from a biological and functional perspective, highlighting what is known about sleep among young children and how it has been studied to date. Second, a review of empirical literature will explore the role of sleep in promoting children's school success, with particular attention to the hypothesized effects of sleep on the development of self-regulation. Finally, a theoretical discussion of sleep in light of underlying, physiological processes of activation will lead to explanations and hypotheses for how sleep affects children's academic experience in the first years of school. 
SLEEP AND CHILDREN'S DEVELOPMENT

\section{Describing Sleep in Early Childhood}

In the following section, a brief summary of the characteristics of and mechanisms behind sleep is offered to provide a foundation for the discussion that follows, after which the sleep of young children more specifically will be described.

Sleep biology. Sleep is a universal part of daily life, a basic human need that takes up almost a third of our lives (Dahl, 2011). Most people intuitively experience sleep as a period of nighttime unconsciousness during which we are unaware of surroundings, out of control of our cognition, and generally unresponsive, and from which we get rest and rejuvenation. During this time, the brain goes through specific changes that characterize the entire sleep period.

Sleep is comprised of REM (rapid eye movement) and non-REM (NREM) periods, which have distinguishable characteristics and functions. REM sleep can be thought of as 'paradoxical sleep' (Dahl, 1996a). During this period, there is notable cortical activation that is disconnected from one's surrounding environment or physical movements (Dahl, 1996a). Unlike the deep phases of non-REM sleep, sleepers wake more easily during REM sleep and regain alertness quite quickly upon waking. It is also during this phase when most dreams occur.

NREM historically has been divided into four stages, although contemporary research combines stages 3 and 4 (Astill et al., 2012). The final phase of non-REM sleep is comprised of slow-wave, delta sleep (SWS), during which brain waves are slowest and unconsciousness is deepest. Dahl (1996a, p.6) describes this period as "recovery" sleep, and this is when partial arousals, sleepwalking, and night terrors may occur. Every phase 
of NREM sleep lasts generally between 70-120 minutes, increasing in length as the night goes on (Carskadon \& Dement, 2005).

Throughout a complete sleep period, the brain rotates through both REM and NREM phases. More NREM phases occur toward the beginning of the sleep period and more REM phases occur towards the end when the body temperature is at its lowest (Dahl, 1996a), which generally results in 75-80\% NREM and 20-25\% REM sleep (Colten \& Altevogt, 2006). Other bodily systems react as the brain cycles through REM and NREM phases, including cardiovascular changes, such as a drop in heart rate and blood pressure, endocrine activity and hormone release, fluctuations in metabolism and cerebral blood flow, drops in muscle tone, and changes in respiration and ventilation (Colten \& Altevogt, 2006). The variations that occur throughout the whole sleep period have dictated features of how sleep is studied and implications for problematic sleep.

The study of sleep. Sleep has traditionally been studied in clinical populations in the form of sleep disorders. These include dyssomnias such as insomnia and hypersomnia, and parasomnias such as somniloquoy (sleep-talking), somnambulism (sleep-walking), and night terrors; recently, there has been a growing interest in sleep disordered breathing — a broad category that includes snoring, obstructive sleep apnea, and other respiratory abnormalities. Disordered sleep, and sleep disordered breathing in particular, has been shown to have far-ranging health implications, both in adults and in children (O’Brien, 2013).

From a practical and functional standpoint, and especially in non-clinical populations, the measurement of sleep frequently addresses sleep quantity and sleep 
quality. Quantity is aligned with duration of sleep period, calculated as time-in-bed and/or actual time spent asleep depending on the measurement technique (discussed further below). Quality is more multi-faceted, however: high quality sleep can be understood as the absence of sleep problems, and poor quality sleep can be described with a number of characteristics that impede restful, regenerative sleep periods. These include: sleep latency, how long it takes someone to fall asleep after they get in bed; sleep efficiency, the percent of the sleep period during which people are actually asleep; night-wakings or sleep disruptions (also called sleep fragmentation), measured as a count of times during the night when someone is awake for 5 minutes or longer; and daytime sleepiness, meant to indicate the un-restfulness of the previous night's sleep.

Multiple methods exist for measuring sleep, and they offer different advantages depending on the focus of research, the age of the participants, and whether researchers are interested in sleep disorders or normative sleep. Although polysomnography is considered the "gold standard of sleep assessments" (Sadeh, 2011, p. 355), it involves many physiological monitors and can only be conducted in very controlled environments. Thus, the majority of research on normative sleep is conducted with either actigraphy or self-report/interview measures. Actigraphy measures body movement and activity with a wearable wrist or ankle band, and this data can be used to evaluate sleep-wake patterns, including active and quiet sleep, with high validity (Sadeh, 2011). Sleep questionnaire and sleep diary methods, by contrast, ask a number of questions either of parents or participants themselves to identify sleep schedules, night-wakings, sleep problems, and other sleep behaviors. These methods are cheaper and more straightforward to collect, 
explaining, in part, their extensive use. Moreover, many validated and standardized measures exist (see Sadeh, 2011). Although data from such assessments are highly correlated with actigraphy measures, parents tend to underreport night-wakings and to slightly overestimate sleep duration as compared with actigraphy data (Tikotsky \& Sadeh, 2001).

Young children's sleep: development and description. Different patterns of normative sleep are evident across the lifespan. Although there is still much to be learned, researchers agree that as humans age, total sleep time, sleep efficiency, and the amount of slow wave sleep all decrease (Ohanyon, Carskadon, Guilleminault \& Vitiello, 2004). Meta-analytic data on lifetime samples suggest that sleep latency, the percent of stage 1 sleep and the percent of stage 2 sleep increase with age, whereas the percent of REM sleep decreases with age in adults and modestly but significantly increases with age in children (Ohanyon et al, 2004). Dramatic changes in sleep patterns occur in infancy, including the emergence of a circadian rhythm around week 10-12 of life (Galland et al, 2012). Children tend to have the greatest amount of slow-wave sleep from ages 3-6, the same years during which daytime naps generally cease (Dahl, 1996a). Evidence suggests that children tend to develop personal tendencies in their circadian rhythm, manifest as a 'morning person' or 'night owl', around age 6 or school entry (Colten \& Altevogt, 2006), and that the precursors of these preferences emerge in infancy (Weissbluth, 1989).

Despite the ample literature on sleep physiology across the lifespan and sleep disorders in children, descriptive studies of normative sleep in early childhood have been underrepresented in the field. 
Responding to a gap in the research (El-Sheikh, 2011), some recent work has attempted to more accurately describe normative sleep during infancy and childhood. In their cross-cultural meta-analysis, Galland and colleagues (2012) found that 4-5 year olds average 11.5 hours of sleep per day with lower and upper limits of 9.9 hours and 13.8 hours; among 6-year-olds, this number drops to 9.7 hours, with limits of 8.1 and 11.4. Cairns and Harsh (2014) found slightly different results in their study of 5-year-olds' sleep patterns across the transition to kindergarten. Per 24-hour period, their small sample of children slept almost 10 hours in the summer before kindergarten and about 30 minutes less than that a month later $(m=9 \mathrm{~h} 53, s d=43 ; m=9 \mathrm{~h} 22 \mathrm{~m}, s d=37.9)$. Some differences did emerge, however, between children who had not attended pre-k and those who had, such that preschool attendees reported less dramatic changes in sleep onset and wake times across the kindergarten transition than those who did not attend preschool (see Cairns \& Harsh, 2014). These findings are in line with pediatric sleep recommendations: 10-13 hours of sleep per diem for 3-5 year olds and 9-12 hours for 612 year olds (Paruthi et al., 2016).

Sleep quality in the pre- and early- school years has been studied less frequently than sleep quantity. Accordingly, in their aforementioned meta-analysis, Galland and colleagues (2012) were unable to analyze sleep quality patterns due to a lack of studies on the topic after babyhood. Some data are available from studies whose primary foci were on other constructs, however. In a 2001 study whose goal was to compare actigraphy and parent-report measures in a white, middle-class sample, $41 \%$ of children exhibited 3 or more night-wakings, and $29 \%$ of children had sleep efficiency lower than 
90\% (Tikotzky \& Sadeh, 2001). More recently, Cairns and Harsh (2014) found similar results: sleep efficiency levels averaged $85.9 \%(\mathrm{sd}=4.0)$ before kindergarten and $88.3 \%$ $(\mathrm{sd}=5.6)$ one month in.

The paucity of descriptive data on normative sleep in this age group means that researchers are still unclear on the thresholds of inadequate sleep. Many in the field have called, therefore, for more work to simply describe childhood sleep patterns in normally developing populations, as well as to explain and understand its dynamics in a biopsychosocial context (El-Sheikh, 2011). More still have called for work in non-white, low-SES, and economically disadvantaged samples (El-Sheikh, 2011), as is discussed in the following section.

Sleep differences: race, socioeconomic status, poverty. In line with other fields that study racial/ethnic differences, psychological and sociological studies have highlighted disparities in African-American and European-American children's sleep. African-American children tend to get less sleep than their European-American peers, which is apparent from preschool (Montgomery-Downs, Jones, Molfese \& Gozal, 2003) through adolescence (Gellis, 2011), even when controlling for household income (McLaughlin Crabtree et al., 2005). However, in young children these differences may not persist when measuring both nighttime and daytime sleep; in one sample, AfricanAmerican children slept less at night but were more likely to make up this time with daytime naps (Crosby, LeBourgeois \& Harsh, 2005). There is also evidence to suggest that African-American children do not suffer from high levels of non-clinical sleep problems when taking SES into account, but that they are at greater risk for obstructive 
sleep apnea even when controlling for SES and obesity (McLaughlin Crabtree et al., 2005; Gellis, 2011).

Poverty, low-SES, and other forms of disadvantage have been studied less directly in relation to sleep, but some helpful work does exist. In one empirical study of school-aged children, lower sleep efficiency and more night-wakings were associated with increased family stress and lower parental education, both of which are related to SES (Sadeh, Raviv \& Gruber, 2000). However, the parents from this sample were mostly well educated and middle-class, which draws into question the generalizability of the results to economically disadvantaged groups. A later study with broader income ranges indicates that children of parents with incomes below the national household median were more likely to display sleep problem behaviors, excessive sleepiness during the day and less sleep at night, even after controlling for race/ethnicity (McLaughlin Crabtree et al., 2005).

In support of these findings, research has documented a number of environmental risk factors disproportionately experienced by poor children that may interfere with their sleep (Evans, 2004; Gellis, 2011). Specifically, lack of household structure and routine may disrupt a child's circadian rhythm and sleep-wake patterns, and crowding at home and high levels of noise may make it difficult for children to fall and stay asleep. In conjunction, these can manifest as a chaotic home environment that may appreciably diminish a child's quantity and quality of sleep.

In summary, research indicates that there are age-related differences in sleep, that young children require many hours of high quality sleep for healthy development, and 
that there are demographic differences in average sleep quantity and quality levels, such that African-American children and children from economically disadvantaged backgrounds tend to have lower quantity and quality of sleep. Given the unique challenges faced by children entering the school system, a further discussion of how sleep is relevant to school outcomes is warranted. A review of the research on this topic proceeds in the next section.

\section{Sleep and School Success: Context and Research}

The first few years of school are crucial for children's academic success, and it is during this time when they learn what will be expected of them as students. Children must internalize the behavioral norms of the classroom, such as raising your hand to ask a question, in addition to developing the educational building blocks of literacy and numeracy. Thus, the skills needed in school span both cognitive abilities that facilitate acquisition of knowledge (Welsh, Nix, Blair, Bierman \& Nelson, 2010) and regulatory abilities that allow for engagement in the classroom (Ponitz, Rimm-Kaufman, Grimm \& Curby, 2009). Maximizing children's school readiness therefore would require supporting their cognitive and regulatory development, which research indicates is related to sleep. Self-regulation and its role in school readiness are discussed below, followed by a review of literature on sleep and academic outcomes.

School readiness and self-regulation. Broadly, self-regulation refers to one's capacity to manage and direct his or her thoughts, feelings, and/or actions. The psychology of self-regulation is a wide-ranging field, with a sprawling conceptual map that is still under debate. It has been characterized as a finite resource, one that depletes 
with use and requires rest or disengagement to regenerate (Baumeister, 2002). Although experts differ in the scope of their definitions (Baumeister \& Vohs, 2007; Blair \& Diamond, 2008), two self-regulatory domains are particularly relevant to the research discussed here: cognitive and behavioral. Cognitive self-regulation overlaps considerably with executive functioning (EF), the brain's processes for attending to, manipulating, and integrating information, which include working memory, inhibitory control, and cognitive flexibility (also called attention shifting) (Blair \& Ursache, 2011; McClelland et al., 2014). Behavioral regulation has a functional definition, and it speaks to young children's ability to 'mind' others and exert effortful control over their actions (Blair \& Raver, 2012). Tasks of behavioral self-regulation are thought to capture children's capacity to harness their cognition towards actionable ends (McClelland et. al, 2014). To regulate behavior, children must mobilize executive functions in concert: if a classroom has a specific hand signal for permission to use the bathroom, for example, its students must use working memory to remember the signal while inhibiting the impulse to get up and run to the toilet. Although there is considerable overlap between these domains, each component of regulation is operationalized distinctly and contributes uniquely to children's academic performance (McClelland, Acock \& Morrison, 2006).

Extensive literature indicates that self-regulation is critical for academic learning and success in the school environment. The ability of children to regulate their behavior in class is a priority for most kindergarten teachers (Bassok, Gibbs \& Latham, 2015), and in the school-readiness literature, different elements of self-regulation have been linked to adaptive classroom behaviors and early school success (Rimm-Kaufman, Curby, Grimm, 
Nathanson \& Brock, 2009; Eisenberg, Valiente, \& Eggum, 2010). Behavioral regulation contributes to the effect of emotion management on children's achievement test scores (Howse, Calkins, Anastopolous, Keane \& Shelton, 2003), and multiple cognitive aspects of self-regulation measured in preschool and kindergarten uniquely explain children's math and literacy development, particularly inhibitory control (Blair \& Razza, 2007).

Across multiple sub-domains, ages, and outcomes, therefore, self-regulation is a critical skill for children entering school. Evidence further suggests that sleep is related to children's regulatory and academic outcomes, as detailed in the following section.

\section{Research Review: Sleep and School Success.}

Cross-sectional designs. Multiple aspects of children and adolescents' sleep have been associated with their academic outcomes. Results of a recent meta-analysis (Dewald, Meijer, Oort, Kerkof \& Bogels, 2010) involving 50 studies of children 8-18 suggest that sleep duration, sleep quality, and daytime sleepiness all have small but significant effects on academic performance, with the largest effect size demonstrated for sleepiness, followed by sleep quality and sleep duration. Larger effect sizes were observed among studies with younger samples, which the authors attribute to the role of sleep in prefrontal cortex development and pre-adolescent growth in this region of the brain. A second, more recent meta-analysis (Astill et al., 2012) of 86 studies of children 5-12 found conflicting results: sleep duration was significantly and positively related to cognition, including executive function, multiple-domain cognitive functioning, and school performance, but it was not significantly related to sustained attention, memory, or intelligence. Additionally, sleep efficiency — the only sleep quality measure included in 
the analysis - was not significantly related to any of the cognitive outcomes.

Furthermore, no significant effects of age were observed across studies. This leaves an unclear picture of the ways in which sleep shapes children's school performance, perhaps, as noted by Astill and colleagues (2012), because such broad age ranges and inconsistent demographic reporting increase the unexplained variance in the analyses.

In recent years, researchers have explored concurrent relations between sleep and school outcomes from preschool to $2^{\text {nd }}$ grade. Sleep duration and variability have been associated with academic and cognitive outcomes, such as intelligence (Liu et al. 2012; Touchette et al., 2007), receptive vocabulary (Vaughn, Elmore-Staton, Shin, \& ElSheikh, 2015; Touchette, et al., 2007), and academic abilities (Diaz et al., 2016). Studies using teacher reports have indicated that children who get inconsistent or less sleep exhibit worse behavior in the classroom during pre-school (Bates, Viken, Alexander, Beyers, \& Stockton, 2002) and elementary school (Fallone, Acebo, Seifer \& Carskadon, 2005). In a recent study of preschool children (Vaughn et al., 2015), sleep duration was not associated with teacher reports of attention and focus, but it was positively associated with children's ability to modulation their activation to suit environmental demands and ability to self-correct on a behavioral regulation task. In the same study, variability of wake onset was associated with levels of reactivity, but other sleep quality measures were not significantly related to any studied outcomes (see Table 1, Appendix A). Moreover, late bedtimes and restricted sleep have been associated with attention difficulties in the classroom (Fallone et al., 2005) and at home (Yokomaku et al., 2008). Concurrent 
associations between sleep and school-related skills are informative, but leave many more avenues unexplored.

Longitudinal designs. Longitudinal designs provide insight into the dynamic interplay between sleep, regulation, and academics. A few recent studies have taken advantage of national samples of data collected from birth through childhood to explore these relations. Touchette and colleagues (2007) looked at sleep duration profiles and their implications for regulation and cognitive skills (see Table 1). Four profiles emerged: short-persistent (consistently less than 10 hours), short-increasing (less than 10 in early childhood, increasing by age 3.5-4), 10-hour persistent, and 11-hour persistent. Children with short sleep duration patterns were more likely to exhibit more hyperactivity-impulsivity, lower receptive vocabulary scores at age 5, and lower nonverbal intelligence at age 6 than their peers with long persistent sleep durations.

Likewise, Williams and colleagues have explored relations between behavioral sleep problems and regulation of emotion and attention (Williams, Berthelsen, Walker \& Nicholson, 2017; Williams, Nicholson, Walker \& Berthelsen, 2016; Williams \& Sciberras, 2016; see Table 1). One study identified normative and non-normative profiles of sleep and regulatory behavior that emerged before school entry and looked at implications of profile membership in the school setting (Williams et. al., 2016). Children who exhibited average or above average emotional and attentional regulation in early childhood and sleep problems that completely disappeared by age $4-5$ comprised the normative profile ( $\mathrm{n}=1989,69 \%$ ); children who had increasing or consistent sleep problems throughout the study and lower mother ratings of emotional and attentional 
regulation in early childhood comprised the non-normative group $(\mathrm{n}=891,31 \%)$. At age 6-7, children in the non-normative group received significantly lower teacher ratings of classroom regulation and prosocial skills and significantly higher ratings of emotional problems and hyperactivity than those in the normative group. Findings from a second study (Williams et. al, 2017) include negative concurrent relations between sleep problems and attentional regulation and indicate that sleep problems are associated with greater emotional regulation problems two years later (see Table 1). The authors concluded that their results support a developmental cascade model in which persistent poor sleep negatively affects emotional regulation, which in turn leads to more sleep problems and poorer attentional regulation as time goes on.

Results of a different longitudinal study, however, suggest a reciprocal direction of causality in the relationship between sleep, regulation, and academic outcomes. Bub, Curtis, and Robinson (2016) examined predictive effects of self-regulation on later sleep outcomes, among a national sample observed from birth through age $15(\mathrm{n}=1023)$. They found that self-regulation at age 4.5 was significantly and positively associated with sleep duration at ages 8 and 11, after controlling for chronic sleep problems. Moreover, children who exhibited poorer self-regulation at age 4.5 also had, on average, significantly more night-wakings and daytime sleepiness at age 8 . These associations waned to marginal significance age 11 , and disappeared by age 15 .

Longitudinal studies have the advantage of mapping the changing relationships between sleep and regulation across time. However, these studies draw from national 
samples that do not capture the nuanced dynamics between sleep and regulation in light of individual characteristics. A few studies address this gap, as described below.

Studies of individual and demographic characteristics. Patterns of individual, demographic, and environmental characteristics situate the dynamic relationship between sleep, self-regulation, and academics in children's contextualized experience.

Components of self-regulation may moderate the relation between sleep and academics: among an ethnically diverse, middle-class sample of kindergarteners, poor sleep quality predicted lower achievement on academic assessments among preschoolers who exhibited low effortful control (EC), but not for those who exhibited high EC (Diaz et. al., 2016). Furthermore, sleep may shape the motivational skills young children bring to school: in a study of predominantly low-income, African-American preschoolers, the predictive pathway between chaotic living circumstances and children's helpless/hopeless responses to academic challenge was partially mediated by problematic sleep (Brown \& Low, 2008).

Sleep also may be a crucial explanatory link in the chain of disadvantage faced by many low-SES, low-income and racial minority students. Multiple components of sleep quantity and quality are negatively associated with different facets of SES, including income-to-needs ratios, parents' perceived economic well-being, parental education, and school-level poverty (El-Sheikh et. al., 2013). Some evidence suggests that this negative relation may be problematic specifically for African-American children, even when controlling for SES (Buckhalt, El-Sheikh, \& Keller, 2007; Buckhalt, El-Sheikh, Keller \& Kelly, 2009; El-Sheikh et. al., 2013). Moreover, the negative effect of poor sleep on 
academic skills is significant for children from low-SES homes, but not their more well off counterparts, a finding that persists two years later, even when controlling for levels at Time 1 (Buckhalt et. al, 2007; Buckhalt et. al., 2009). In this context, SES stands in for a complex ecology of environmental factors that may underlie the statistical interaction between sleep, social address and academics. Such findings sketch a bleak picture for children with many factors of cumulative risk in which limited resources and multiple modes of disadvantage both engender poor sleep and exacerbate its effects.

Summary. Taken together, the literature on sleep and schooling sheds light on a connection between sleep and self-regulation that is visible and measurable for both parents and teachers, and that has implications for key academic outcomes. Evidence suggests that problematic sleep can have detrimental effects on children's school performance and cognitive functioning, although a consensus has not emerged about which sleep characteristics are most directly related to academic skills (Beebe, 2011). This dynamic can manifest in observable trajectories of risk across time, and implications are particularly severe for poor, low-SES, and African-American children.

In spite of a growing body of research, the active mechanisms driving associations between sleep, self-regulation, and academics remain opaque. As with many emerging fields, attempts to draw conclusions from the literature are complicated by the different sleep characteristics, operationalization of outcomes, and measurement methodologies available to researchers. Few studies frame the impacts of poor sleep as comprising both regulatory and academic outcomes, and to this author's knowledge, to date no studies have examined a causal pathway linking these three critical constructs. 
Therefore, the final section of this chapter describes a theoretical rationale for integrating sleep and regulation into the study of child development at the advent of school.

\section{Theoretical Connections: Sleep, Self-Regulation and Academics}

Multiple theories that explain the integration of sleep-wake processes, arousal, and stress shed light on how and why insufficient sleep may be detrimental to young children's performance in school. Below, the physiological regulation of sleep and wakefulness will be explained, including a discussion of how these processes are relevant to the waking brain and young children at school. Finally, the detrimental effects of insufficient sleep will be described and sleep problems will be situated in a broader context of cumulative risk in light of individual differences and environmental factors.

Sleep, regulation, and arousal: processes and physiology. According to Borbély's two process model $(1982,2016)$, sleep is regulated by two distinct mechanisms: a sleep dependent process and a sleep independent circadian process. In the former, the body's need for sleep increases the longer it has been awake, and homeostasis can only be achieved by sleeping. Thus this sleep homeostat is a purely internal process, driven only by how much (or how little) sleep a person has recently had. By contrast, the circadian timing system (also known as circadian rhythm) regulates hunger, sleep and other biological functions through hormonal secretions entrained to the time of day. Through this second mechanism, sleep becomes synchronized with levels of cortisol and other stress hormones that have broad, domain-general effects on the nervous system. In light of these dual processes, Weissbluth (1989) articulates that the two 'macrostates' of sleep and wakefulness are 'asymmetric': sleep can overcome wakefulness only 
depending on the aforementioned processes, whereas wakefulness can wholly override sleep if required by the circumstance (discussed below). There are, therefore, two pathways of vulnerability that may determine how and why someone sleeps poorly.

Dahl (1996a) argues in favor of a conceptualization of sleep that fits into a larger process of arousal and activation. First, similar brain structures are involved in regulating sleep and regulating affect and attention. Often patients with disorders in one of these domains have difficulty in another, as evidenced by the comorbidity of sleep disorders and ADHD, for example. Second, because sleep is marked by such a dramatic decrease in vigilance (awareness), it must be integrated into the body's overall system for dealing with safety and threat. When faced with an environmental threat, the brain must override the need for sleep in order to maintain the necessary arousal to survive in the face of danger. Such activation may have commonalities with the fight or flight response, including release of cortisol and other stress hormones. This sleep-inhibiting hyperactivation is fundamentally opposed to the circadian sleep-wake cycle, in which sleep is an essential state for cognitive regeneration and maturation.

Drawing on this earlier work, Astill and colleagues (2012) summarize four psychobiological hypotheses for how sleep affects the waking brain, especially among children: 1) the trace reactivation/replay hypothesis suggests that sleep allows for memory consolidation working through connections between the hippocampus and the neocortex and medial prefrontal cortex; 2) the synaptic homeostasis hypothesis suggests that sleep allows for a downgrading or reduction in synaptic firing that prevents overload and saturation, such that sleep deprivation results in overstimulation of the neocortical 
and limbic circuits; 3) sleep supports the frontal integrity of the frontoparietal networks that are important for sustained attention, thus fending off activation of a 'default mode network'; and 4) the overnight therapy hypothesis posits that sleep allows systems that regulate emotion and arousal, like the limbic system, to reset, which could explain why some of the behavioral markers of sleep deprivation are emotional reactivity and dysregulation. The brain structures involved in these different hypotheses- the neocortex, prefrontal cortex, and frontoparietal network-are still developing in young children, which may explain differences that have emerged in empirical work on how children and adults respond to poor quality sleep and sleep deprivation. Indeed, as the prefrontal cortex in particular develops throughout childhood, its role in modulating and integrating higher order processes may contribute to age-related differences in the outcomes of sleep deprivation observed between early childhood and adolescence (Dahl, 1996b).

Risks of insufficient sleep. Weissbluth (1989) presents a model of sleep-loss stress, drawing from empirical research and observations from pediatric practice, and describes its implications for temperament in infants and young children. In this model, the outwardly observable, behavioral pattern is that of sleep loss resulting first in fatigue or sleepiness but then in hyper-alertness that, if it persists, becomes a 'too-wakeful state' marked by emotional reactivity and difficult temperament. Underpinning this pattern of behavior is a chain of neurochemical changes: 1) sleep loss is associated with increased cortisol, which regulates production of epinephrine; 2) increased epinephrine-also associated with sleep loss and perceptions of fatigue - raises levels of activation and 
alertness, which sometimes manifest as anxiety or even fear; 3 ) as heightened alertness becomes prolonged, the brain becomes overwhelmed with norepinephrine, which creates the 'too-wakeful state' and, combined with the other neurochemical changes, produces the emotional reactivity and difficult temperament mentioned above. This may explain Dahl's clinical observation that inadequate sleep in children often manifests not in behaviors that resemble 'sleepiness' (low arousal), but rather in over-activation, including frustration, crankiness, and short attention span (1996b).

Such over-activation may have implications in the context of school readiness. As Blair and Raver (2015) articulately describe, the relation between regulationparticularly that of attention - and arousal can be mapped as an inverted U-shape: while very low and very high levels of reactivity diminish executive function and attention, moderate levels of activation maximize executive function and attention by stimulating the prefrontal cortex and the release of cortisol. The implications in the school setting, therefore, mean that if a child's level of activation is too low or too high, as in the case of sleep-loss stress, they may be unable to adequately attend and self-regulate. This pathway may explain recent results by Scher, Zaidman-Zait and Weinberg (2010), in which 1-3 year olds who experienced more fragemented sleep had higher waking cortisol levels, which in turn were correlated with lower ratings of behavior by childcare teachers.

Certain individual and contextual factors may increase the risk that one's sleep problems will affect his or her school life. First, individuals have unique sleep patterns and preferences that emerge during early infancy and continue to manifest into adulthood, resulting in relatively stable tendencies towards being a 'morning person' or 
'night owl', for example (Weissbluth, 1989). The degree to which a child's intrinsic patterning fits the schedule reinforced by their environment can result in smooth sailing or in compounding vicious cycles of sleep loss and stress. Second, characteristics of temperament may dictate how a child dealing with sleep-loss stress responds to school challenges, such as whether it manifests as internalizing or externalizing behavior, or in hyperactivity (Molfese, Rudasill \& Molfese, 2013). Third, the demands of the school context specifically may place additional burden on the neurological systems that are most sensitive to sleep-loss (Dahl, 1996b). As discussed earlier, school success necessitates synchronized functioning of higher order cognitive processes to allow students to observe and manage the social, emotional, and behavioral demands that coalesce in the classroom. For young children whose brains are actively developing, the sudden uptick in environmental demands across the transition to school may create a confluence of challenge that is exacerbated by poor sleep.

According to a developmental systems perspective, a child's early school experience is shaped by personal characteristics and prior experiences, derived in part from one's economic, cultural, and socio-economic environment. Empirical evidence reported above shows that children who grow up in poverty and who are AfricanAmerican suffer from a greater incidence of sleep problems (e.g. Gellis, 2011; Montgomery-Downs et. al, 2003). Moreover, accumulated stress due to economic disadvantage affects children on a physiological level, such that children in poverty have higher baseline levels of activation (allostatic load) (Evans \& Kim, 2013). 
In light of this research and the theories presented, underlying physiological risk may make disadvantaged children more likely both to experience poor sleep and to have it affect their school success. This may be especially so of children for whom protective factors, like an organized home environment and positive teacher-child relationship, are not present. Therefore for some children, sustained activation due to allostatic load and increased reactivity due to sleep-loss stress may create the perfect storm of disadvantage in light of the already challenging task of regulating oneself at school. 


\section{Chapter 3: Current Study}

The purpose of this study is to explore the role of sleep in young children's development of two skills critical for school success: self-regulation and academic competencies. This study intentionally focuses on a predominantly African-American, economically disadvantaged population, who the literature shows may be at greater risk for sleep related difficulties and lower school-related skills at kindergarten entry.

This research can make valuable contributions to the study of childhood sleep and the study of school readiness. As previously discussed, experts have explicitly called for more sleep research among children in pre-k through $3^{\text {rd }}$ grade, among children from racially and socioeconomically diverse backgrounds, and utilizing longitudinal designs (El Sheikh, 2011). The study contributes descriptive data about sleep in these populations, and uses a longitudinal design to address its role in development. Furthermore, a more in-depth understanding of sleep's role in school readiness can provide actionable information for educators and caregivers. Although much school readiness literature addresses the skills and environments that facilitate success at school entry, an understanding of sleep in this context may help clarify the connection between biological phenomena and development of such skills. It may provide a lens through which to better understand problems that individual children have in school, and it could inform choices at the level of administrators or policy-makers.

In light of these goals and the prior literature review, the following section outlines the research questions and hypotheses of the current study. 


\section{Research Questions and Hypotheses}

Research Question 1: Is the quality and quantity of children's sleep associated with their development of academic skills?

Hypothesis 1a: Kindergarteners and first graders with greater sleep quantity will demonstrate greater development of math and literacy skills during one calendar year.

Hypothesis 1 b: Kindergarteners and first graders with higher quality of sleep will demonstrate greater development of math and literacy skills during one calendar year.

Research Question 2: Is the association between quality and quantity of sleep and children's development of academic skills stronger for younger children?

Hypothesis 2a: The contribution of sleep quantity to improvements in children's development of math and literacy skills will be relatively stronger among kindergarteners than $1^{\text {st }}$ graders.

Hypothesis $2 \boldsymbol{b}$ : The contributions of sleep quality to improvements in children's development of math and literacy skills will be relatively stronger among kindergarteners than $1^{\text {st }}$ graders.

Research Question 3: Is the quality and quantity of children's sleep associated with the development of their ability to self-regulate?

Hypothesis 3a: Kindergarteners and first graders with greater sleep quantity will demonstrate greater development of self-regulation skills during one calendar year.

Hypothesis $3 \boldsymbol{b}$ : Kindergarteners and first graders with higher quality of sleep will demonstrate greater development of self-regulation skills during one calendar year. 
Research Question 4: Is the association between quality and quantity of sleep and children's development of self-regulation skills stronger for younger children?

Hypothesis 4a: The contributions of sleep quantity to improvements in children's development of self-regulation skills will be relatively stronger among kindergarteners than $1^{\text {st }}$ graders.

Hypothesis 4b: The contributions of sleep quality to improvements in children's development of self-regulation skills will be relatively stronger among kindergarteners than $1^{\text {st }}$ graders.

Research Question 5: Is the relation between children's quantity and quality of sleep and their development of academic skills explained, in part, by their development of self-regulation skills?

Hypothesis 5: The effect of sleep quality and quantity on children's development of math and literacy during one calendar year will be significantly but partially explained by the relation between their development of self-regulation and their development of academic skills during one calendar year.

Taken together, these hypotheses predict that children who get better sleep will be better able to self-regulate and learn in the classroom, thus demonstrating more growth in these school-related skills over a calendar year (Hypotheses 1a, 1b, 3a, 3b). Furthermore, it is hypothesized that the benefits of better sleep will be more important for kindergarteners than first graders, because literature shows that younger children need more sleep (Hypotheses 2a, 2b, 4a, 4b). Finally, it is hypothesized that better sleep will allow children to better regulate themselves in the classroom, which will in turn allow 
them to learn more during school and thus demonstrate greater academic growth (Hypothesis 5). The figure below depicts the hypothesized theory of change and corresponding research questions.

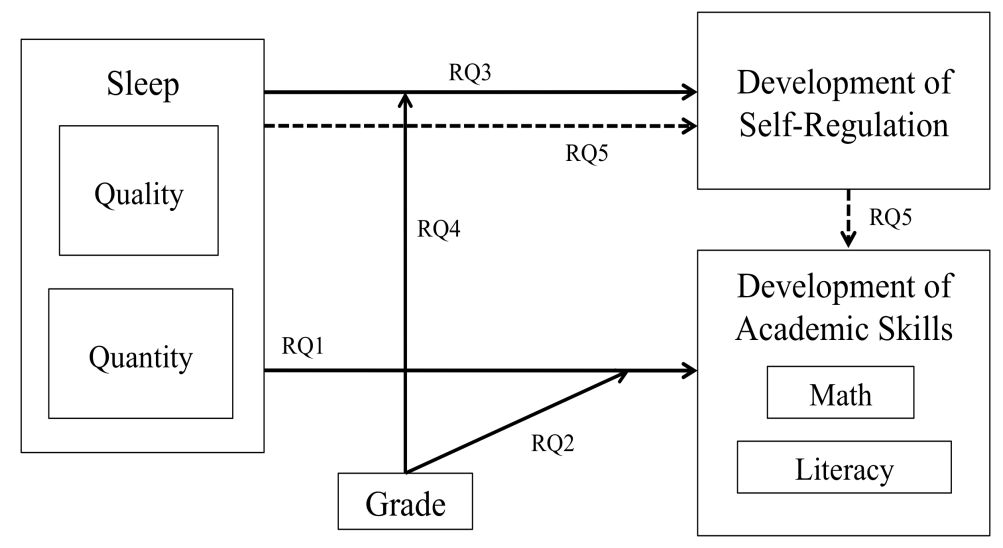

Figure. 1. Model and Research Questions 


\section{Chapter 4: Methods}

Data for this project was collected as part of the WINGS impact study, an evaluation of the WINGS for Kids afterschool program (WINGS), which was conducted from 2011-2015 in Charleston, SC. The program is an afterschool social-emotional learning (SEL) program administered in high-need schools in North Charleston and runs daily during the school year from the end of the school day to $6 \mathrm{pm}$. The WINGS curriculum includes structured activities intended to develop five key SEL competencies: 1) self- awareness, 2) self-management, 3) responsible decision-making, 4) social awareness, and 5) relationship skills (WINGS for Kids, 2013). Students who participate

in WINGS range from kindergarten through $5^{\text {th }}$ grade, and admission into the program is based on need. The population from which WINGS students are drawn is socioeconomically disadvantaged; over $90 \%$ of the students in the area qualify for free or reduced lunch and most families fall below $200 \%$ of the poverty level for the nation.

The WINGS impact study was a block randomized control trial (by cohort and school) intended to assess the effects of offering access to WINGS for entering kindergarteners on their short- and long-term SEL and academic outcomes. Data was collected from parent and teacher interviews, child observations, and child direct assessments to measure children's social-emotional competencies, academic abilities, school and home relationships, and school and home behavior. Interviews with parents were conducted to describe the home lives and experiences of children who participated in the WINGS program evaluation. Funding was provided by the Institute for Education Sciences and the Social Initiatives Fund. 


\section{Participants}

Participants in the current study come from two cohorts of the WINGS impact study. Children in kindergarten and $1^{\text {st }}$ grade in Fall of 2014 were included $(\mathrm{n}=212 ; 109$ girls). The analyses include children from both control and treatment groups. Among the participants for whom we have demographic information ( $\mathrm{n}=182), 85.4 \%$ are AfricanAmerican, $95.5 \%$ are eligible for free or reduced lunch, and $36 \%$ of mothers have educational attainment beyond high school.

\section{Procedures}

Data was collected from the aforementioned sample at two time points: Fall of 2014 (Time 1) and Fall of 2015 (Time 2). Sleep questions (described below) were asked as part of an interview given by trained staff to children's primary caregivers, administered at Time 1. Child direct assessments (described below) were administered 1on-1 by trained assessors in the afterschool setting at both Time 1 and Time 2 .

\section{Measures}

Sleep quantity. Sleep quantity was operationalized as time-in-bed as reported by caregivers. Answers to the questions "What time did your child go to bed on a school night during the school year?" and "On school days what time does your child usually wake up?", reported in hours, were used to calculate a child's sleep duration.

Sleep quality. Sleep quality comprises sleep latency, sleep disruption, and difficulty waking because, as previously described, poor quality sleep can take on multiple forms and result from different causes. Sleep fragmentation can disrupt sleep cycles, whereas delays in falling asleep can indicate a mismatch between a child's 
circadian sleep pattern and the demands of their environment. Finally, difficulty waking in the morning indicates a lack of restfulness, which can be a result of insufficient or poor quality sleep, or a misalignment of their circadian and school schedules. The items are not highly correlated (see Table 3), suggesting that they are not indicators of a single factor. Therefore, in light of the distinct theoretical causes of each sleep quality measure and the low amount of variance that they share, it was decided to analyze each measure of sleep quality (e.g. disruption, latency, difficulty waking) separately.

Sleep Latency. Sleep latency was measured using caregiver responses to the following question at Time 1: "How long after going to bed does your child usually fall asleep?" (reported on a 5 point scale of 15 minute intervals ranging from 'Less than 15 minutes' to 'More than 60 minutes'). Because of the low number of children who were reported as falling asleep within ' $45-60$ minutes' $(n=5,3.18 \%$ of the sample) and 'More than 60 minutes' ( $\mathrm{n}=5,3.18 \%$ of the sample), the last two categories were collapsed to form a four point scale in which $0=$ 'Less than 15 minutes', 1='15-30 minutes', 2='30-45 minutes', and 3='More than 45 minutes'. This modified scale was used for analyses.

Sleep Disruption. Sleep disruption was measured using caregiver responses to the following question at Time 1: "How many times does your child usually wake up during the night?" (reported on a 3 point scale ranging from 'None' to 'More than 2 times'). For the majority of the sample, parents reported that children did not wake up during the night $(\mathrm{n}=103)$. Response categories for ' $1-2$ times' and 'more than 2 ' times were collapsed because of limited variability, resulting in a dichotomous variable indicating whether or not children woke up during the night that was used for analyses. 
Difficulty Waking. Difficulty waking was measured using caregiver responses to the following question at Time 1: "How easy or hard is it to get your child up in the morning?" (reported on a 4 point Likert-type scale ranging from 'very easy' to 'very hard').

Self-regulation. Self-regulation was measured with the Head Toes Knees Shoulders (HTKS) assessment of behavioral self-regulation. In the assessment, children learn four paired behavioral rules: "Touch your head" and "Touch your toes", and "Touch your knees" and "Touch your shoulders". In the first round they respond naturally; in the second round they are instructed to respond with the opposite motion (i.e. touching shoulders when told "Touch your knees"), and in a final round the pairings are switched. The task requires children to use working memory, inhibitory control and attention shifting, and has demonstrated high inter-item and inter-rater reliability, as well as construct and predictive validity (McClelland et al., 2014).

Academic abilities. Two key academic abilities, emergent literacy and mathematical reasoning, were measured by the Letter-Word and Applied Problems tasks from the Woodcock Johnson-III Tests of Achievement (WJ-III, Houghton-Mifflin Harcourt). The Letter-Word sub-test assesses children's ability to visually identify and name letters and words. The Applied Problems sub-test assesses children's ability to solve and analyze numerical and spatial problems administered verbally with accompanying pictures. The WJ-III is a widely used battery that measures academic skills and abilities for individuals aged 5-95; sufficient reliability $(\alpha>0.80)$ and validity has been demonstrated for the subtests and battery as a whole (Dean, 2011). 
Covariates. Child's sex, reported by parents, was included as a covariate to control for gender differences on child outcomes. Literature suggests that during kindergarten, boys perform less well on self-regulation tasks than girls (Matthews, Ponitz $\&$ Morrison, 2009). Child's treatment/control status at randomization was included as a covariate to address any effects of the intervention. In addition to sex and treatment condition, child and family characteristics that may affect children's development were included in the models: ratio of children to adults at home, number of moves within the last year (mobility), maternal level of education (1= 'Less than High School', 2= 'High School or Equivalent', 3= 'High school, some college/technical', 4= 'College degree, plus'), whether the child had previously attended Pre-K ( $0=$ 'No', $1=$ 'Yes'), and financial strain. Financial strain was calculated as an average of three questions, rated on a 5 point Likert-type scale ranging from 'Not at all difficult' to 'Very difficult': "How difficult is it for you to live on your total household income right now?", "In the next two months, how much do you anticipate that you or your family will experience actual hardships such as inadequate (meaning NOT adequate) housing, food, or medical attention?", "In the next two months, how much do you anticipate having to reduce your standard of living to the bare necessities of life?". All child and family characteristic covariates were reported by caregivers at Time 1 (Fall 2014).

Moderators. Child's grade at Time 1 (Fall 2014) was used as moderator. 


\section{Chapter 5: Results}

All data analyses were conducted using the RStudio interface for R statistical programming language (version 3.2.4, 'Very Secure Dishes'), including the lavaan package (Rosseel, 2012).

\section{Preliminary Analyses}

Of the three outcome variables, literacy and mathematical reasoning exhibited appropriate distributions for inclusion in regression analyses, but self-regulation exhibited some non-normality. There was a considerable floor effect on the measure of selfregulation in that 50 children $(27.4 \%)$ of children demonstrated 0 correct responses at baseline. This number fell to 12 only $(12.9 \%)$ at Time 2 . Due to the robustness of the assumptions of multiple linear regression, this measure was included in the analyses without transformation.

There was data missing in this data set. As previously noted, sleep was assessed through parent interviews, which were collected at baseline for 158 of the 212 children (74\%). Baseline direct assessment data was collected from 182 children in the Fall of 2014, which dropped to 137 in the Fall of 2015. In total, 101 out of 212 children had complete data for all predictor and outcome variables. Missing data can cause biased results depending on the nature of the missingness, which can be described as: Missing Completely At Random (MCAR) if there is no systematic relationship between the missing data, Missing At Random (MAR) if there may be a systematic relationship between the data that is missing but not the data that is available, or Missing Not At 
Random (MNAR) where there is a systematic relationship between the data that are missing and the data that are available. The results of a nonparametric test of homoscedasticity, which tests the hypothesis of MCAR by comparing available data to a single imputed data set (Jamshidian, Jalal \& Jansen, 2014), indicate that although there is evidence of nonnormality in the data set (discussed below), the MCAR hypothesis cannot be rejected at the $\mathrm{p}<.05$ level $(\mathrm{p}=.39)$. Although listwise deletion can be used with MCAR data, Full Information Maximum Likelihood (FIML) takes advantage of all available data to estimate regression coefficients and thereby mitigates potential bias in the results and maximizes sample size (Enders, 2001). Therefore, this estimation method was used for all regression and mediation analyses.

\section{Descriptive Analyses}

Sleep. Results from analyses describing children's sleep (Table 2) indicate that children in this sample averaged 9.79 hours of sleep $(s d=0.76)$ on a normal school night. Five children exhibited sleep durations that fall outside of 3 standard deviations from the mean and thus can be considered outliers; however, these outliers were retained for analyses because they represent realistic amounts of sleep for the sample population. Most children did not experience problems with sleep quality, as evidenced by the low means and standard deviations in the sample. Sleep quantity in the present study is similar to that found by Cairns and Harsh (2014) in their ethnically diverse sample of American children entering Kindergarten $(m=9.88 \mathrm{hrs})$. As discussed in Chapter 2, empirical research does not clearly indicate what can be considered normative sleep quality. However, sleep disruption levels in the present study are much lower than those 
found by Tikotsky and Sadeh (2001), in which $41 \%$ of kindergarteners had 3 or more night-wakings. Finally, as expected based on prior literature, sleep quantity, sleep latency, and sleep disruption were not significantly correlated (Dewald et al., 2010; Table 3). Difficulty waking, however, was significantly albeit modestly correlated with sleep quantity $(r=-.17, p<0.05)$ and with sleep latency $(r=0.27, p<0.001)$.

Three sets of independent sample t-tests indicate that at baseline there were no significant mean level differences in sleep quantity or sleep quality between cohorts or treatment conditions. Although there were no sex differences in levels of sleep quantity, disruption, or latency, boys had significantly more difficulty waking up in the mornings than girls $(t(156)=-2.70, p<0.01$; boys: $m=1.29, s d=1.14$; girls: $m=0.85, s d=0.91)$.

Outcomes. On average, the current sample of children demonstrated growth across one calendar year in their academic skills, scoring significantly higher in math $(t(121)=18.63, p<.001)$, literacy $(t(121)=19.62, p<.001)$, and self-regulation $(t(121)=6.31$, $p<.001$ ) at Time 2 (see Table 2). Compared to the standardized scores available for the Woodcock Johnson $(m=100, s d=15)$, the children in the current sample demonstrated similar abilities at Time 2 (standardized scores: math: $m=93.32, s d=11.6$; literacy: $m=104.85, s d=13.29)$. This is unexpected given previous research on this population as reported in Chapter 2, although it may reflect changes in the normative sample since the Woodcock Johnson-III tests were published in 2002. Furthermore, in this sample of children, academic and self-regulatory outcomes at Time 1 and Time 2 were all highly correlated (see Table 3), which is in keeping with results from prior literature. 
Independent sample T-tests indicate that, on average, girls score significantly higher than boys on tasks of self-regulation $(t(179)=2.68, p<.001)$, emergent literacy $(t(179)=2.10, p<.05)$, and mathematical reasoning $(t(173)=2.13, p<.05)$. Independent sample $\mathrm{T}$-tests also show that $1^{\text {st }}$ graders score significantly higher than kindergarteners on math $(t(111)=-8.20, p<.001)$, literacy $(t(131)=-9.51, p<.001)$, and self-regulation $(t(135)=-4.38, p<.001)$, which is expected given the cumulative nature of these skills.

Bivariate Associations. Inspection of the correlation matrix of sleep and schoolrelated variables (Table 1) reveals inconsistent patterns of relations. As previously mentioned, sleep quantity, latency, and disruption were not significantly correlated. Difficulty waking, however, was modestly but significantly correlated with sleep quantity $(r=-.17, p<.05)$ and sleep latency $(r=.27, p<.01)$. This indicates that some children may be less well rested in the morning if they spent less time in bed or took longer to fall asleep. Notably, however, this is not the case for sleep disruption $(r=.04, \mathrm{~ns})$, which suggests that waking during the night may not relate to children's ease of waking in the morning.

For the most part, baseline academic and regulatory skills were not significantly correlated with the sleep; however, two notable associations emerged. Difficulty waking was negatively correlated with math scores $(r=-.24, p<.01)$, such that children with more difficulty waking tended to score lower on Time 1 math assessments. Sleep disruption was negatively correlated with self-regulation $(r=-.18, p<.05)$, such that children who tend to wake up at night demonstrate poorer self-regulatory skills at baseline. There is not a significant correlation, however, between baseline sleep disruption and Time 2 self- 
regulation. Of the associations between Time 1 sleep and Time 2 outcomes, only literacy was significantly correlated with difficulty waking $(r=-.23, p<.05)$; this relation is explored further in the main analyses below.

\section{Main Analyses}

Research Question 1: Is the quality and quantity of children's sleep associated with their development of academic skills?

Literacy. It was hypothesized that children who get more and higher quality sleep would demonstrate greater development of literacy skills over one calendar year (Hypotheses 1a, 1b). To test this hypothesis, a multiple regression analysis was conducted in which children's Time 2 literacy scores were regressed onto the four sleep variables while controlling for baseline literacy, grade, and child and family characteristics. There was mixed support for this hypothesis: results of a multiple regression analysis show no significant association between literacy development and children's sleep quantity, latency, or disruption when controlling for child and family characteristics and baseline literacy scores (Table 4). However, there was a significant association between difficulty waking and children's development of literacy skills $(B=-$ $4.30, \mathrm{p}=.05$ ), such that a child who finds it very easy to wake up in the morning will score 4.30 points higher on the literacy assessment at Time 2 than a child for whom it is somewhat easy to wake up. Although this relation represents a fairly small effect $(\beta=-$ .12) by conventional standards (Cohen, 1988), this means that, all else being equal, a child for whom it is very easy to wake up in the morning scores 12.9 points higher $(.35$ 
standard deviations) on the literacy assessment at Time 2 than a child for whom it is very difficult to wake up.

Math. It was hypothesized that children who get more and higher quality sleep would demonstrate greater development of mathematics skills over one calendar year (Hypotheses 1a, 1b). To test this hypothesis, a multiple regression analysis was conducted in which children's Time 2 Math scores were regressed onto the four sleep variables while controlling for baseline math scores, grade, and child and family characteristics. Results did not support the hypotheses: sleep quantity, latency, disruption, and difficulty waking did not significantly predict math development (Table 4).

Research Question 2: Is the association between quality and quantity of sleep and children's development of academic skills stronger for younger children?

Literacy: It was hypothesized that the positive association between sleep quantity and sleep quality and children's development of literacy skills would be relatively stronger among kindergarteners than $1^{\text {st }}$ graders. To test this hypothesis, four multiple regression analyses were conducted in which children's Time 2 literacy scores were regressed onto each sleep variable, grade, and the coordinating interaction terms (crossproduct of grade and the sleep variable), while controlling for baseline literacy, the other sleep variables, grade, and child and family characteristics.

Results show nonsignificant interaction effects of grade and sleep quantity $(B=-$ $6.03, p=.28)$, sleep latency $(B=-2.98, p=.54)$, sleep disruption $(B=10.38, p=.23)$, and difficulty waking $(B=5.34, p=.19)$ on kindergarteners and $1^{\text {st }}$ graders literacy 
development. This indicates that there is not a statistically significant difference in the association of sleep and literacy development between the two grades.

Math. It was hypothesized that the positive association between sleep quantity and sleep quality and children's development of math skills would be relatively stronger among kindergarteners than $1^{\text {st }}$ graders. To test this hypothesis, four multiple regression analyses were conducted in which children's Time 2 math scores were regressed onto each sleep variable, grade, and the coordinating interaction terms (cross-product of grade and the sleep variable), while controlling for baseline math, the other sleep variables, and child and family characteristics.

Results show non-significant interaction effects between grade and sleep quantity ( $B=3.51, p=.21)$, sleep latency $(B=-1.97, p=.43)$, sleep disruption $(B=-5.93, p=.17)$, and difficulty waking $(B=.19, p=.67)$ on kindergarteners' and $1^{\text {st }}$ graders' math development. This indicates that there is not a statistically significant difference in the association of sleep and math development between the two grades.

Research Question 3: Is the quality and quantity of children's sleep associated with the development of their ability to self-regulate?

It was hypothesized that children who experience greater quantity (Hypothesis 3a) and quality (Hypothesis 3b) of sleep would demonstrate greater development of selfregulation skills across one calendar year. To test this hypothesis, a multiple regression analysis was conducted in which children's Time 2 self-regulation scores were regressed onto the four sleep variables while controlling for baseline self-regulation, grade, and child and family characteristics. These hypotheses were not supported by the results: 
sleep quantity, sleep latency, sleep disruption, and difficulty waking were not significantly associated with self-regulation skills (see Table 4).

Research Question 4: Is the association between quality and quantity of sleep and children's development of self-regulation skills stronger for younger children?

It was hypothesized that the positive association between sleep quantity (hypothesis 4a) and sleep quality (hypothesis 4b) and children's development of selfregulation would be relatively stronger among kindergarteners than $1^{\text {st }}$ graders. To test this hypothesis, four multiple regression analyses were conducted in which children's Time 2 self-regulation scores were regressed onto each sleep variable, grade, and the coordinating interaction terms (cross-product of grade and the sleep variable), while controlling for baseline self-regulation, the other sleep variables, and child and family characteristics. The results do not support hypothesis $4 \mathrm{a}$ or hypothesis $4 \mathrm{~b}$ (see Table 5). There were no significant interaction effects of grade and sleep quantity $(B=1.05, p=.79)$, sleep disruption $(B=.72, p=.92)$, or difficulty waking $(B=2.03, p=.49)$, such that the differential role of each sleep characteristic in kindergarteners' and $1^{\text {st }}$ graders' selfregulation development was not statistically significant. However, evidence suggests that sleep latency may relate to differently to kindergarteners' and $1^{\text {st }}$ graders' self-regulatory development, as described below.

Results of a moderated multiple regression show a marginally significant interaction effect of grade and sleep latency $(B=-5.84, p=.09)$ on kindergarteners and $1^{\text {st }}$ graders self-regulation development. A plot of the interaction (Figure 2) reveals two different patterns in the two grades: all else being equal, $1^{\text {st }}$ graders who fall asleep 
within 15 minutes score almost 8 points higher on Time 2 self-regulation assessments than those who fall asleep in 45 minutes or more, whereas kindergarteners who fall asleep within 15 minutes score 10 points lower than those who fall asleep in 45 or more minutes.

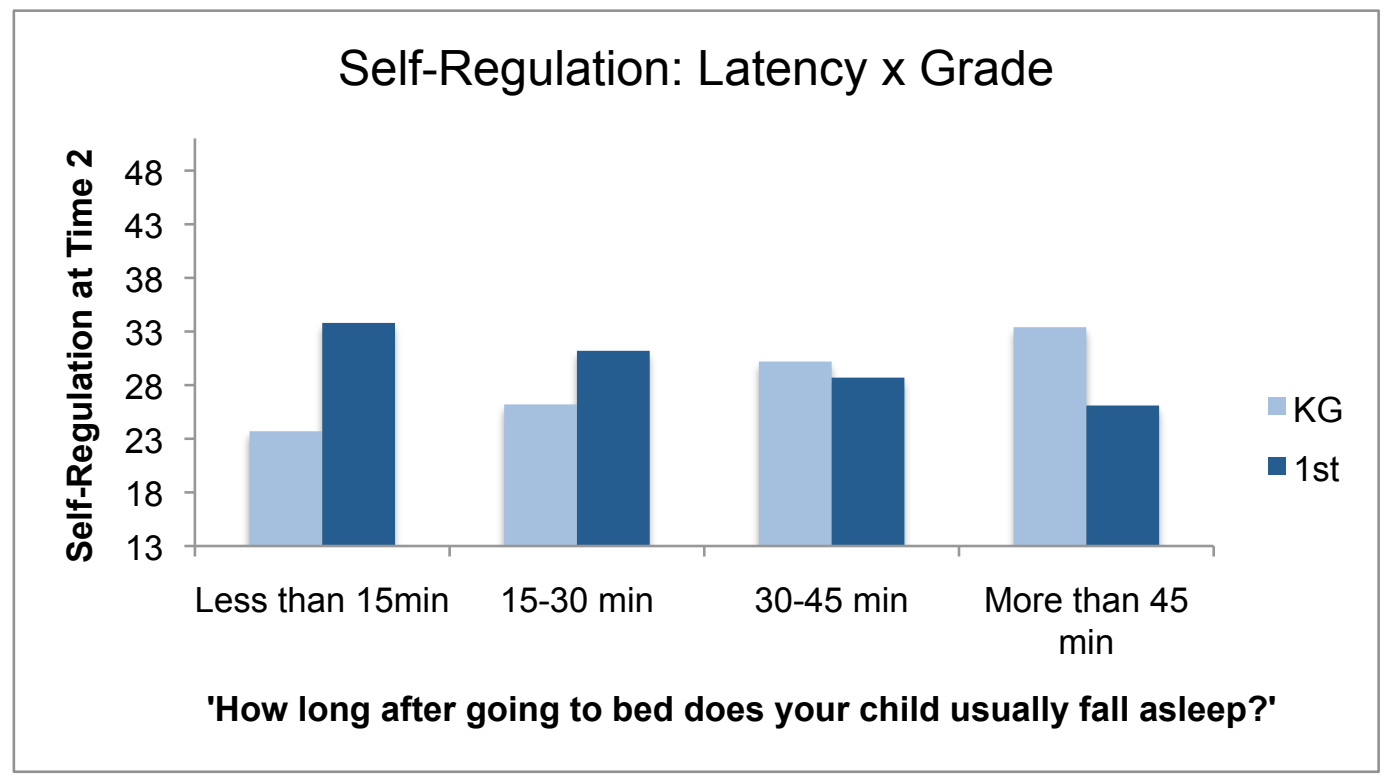

Figure 2. The relation between sleep latency and self-regulation scores at Time 2, for kindergarteners and $1^{\text {st }}$ graders.

To better understand the role of grade in this relation, follow-up analyses were conducted for each grade separately. Results indicate that the role of sleep latency in self-regulatory development is of similar magnitude but opposite sign for kindergarteners and $1^{\text {st }}$ graders. When controlling for baseline self-regulation, the other sleep quality and quantity variables, and child and family covariates, the association between sleep latency at baseline and self-regulation one year later was positive for kindergarteners $(B=3.94$, $\mathrm{p}=.10)$ and negative for $1^{\text {st }}$ graders $(\mathrm{B}=-3.69, \mathrm{p}=.13)$. The results for both grades do not meet the stringent standards of $p<.05$ significance, but they can be interpreted with 
tentative confidence as approaching significance and indicative of a trend. In this light, the findings suggest that sleep latency may be associated with greater self-regulatory development for kindergarteners and poorer self-regulatory development for $1^{\text {st }}$ graders.

Research Question 5: Is the relation between children's quantity and quality of sleep and their development of academic skills explained, in part, by their development of self-regulation skills?

It was hypothesized that the effects of sleep quality and quantity on children's development of math and literacy skills across a calendar year would be significantly but partially explained by the relation between their development of self-regulation and their development of academic skills. To investigate this hypothesis, two path models were tested: self-regulation mediating the path between sleep and math skills (model 1) and self-regulation mediating the path between sleep and literacy skills (model 2), where selfregulation and academic outcome variables were predicted by the four sleep variables controlling for baseline levels, grade, and child covariates. Path model tests of indirect effects provide an alternative to Baron and Kenny's (1986) stepwise method by simultaneously calculating coefficients for predictor on the outcome without the mediator (direct effects) and through the pathway of the mediator (indirect effects). Focusing on the significance and magnitude of indirect effects is recommended in meditational analyses because a significant indirect effect can occur even if there is no significant direct or total effect (Rucker, Preacher, Tormala \& Petty, 2011). Partial or full mediation can be established based on significance tests of the indirect effect, which is calculated as the product of paths from the predictors to the mediator and from the mediator to the 
outcome (Rucker, Preacher, Tormala \& Petty, 2011). Bootstrapped standard errors provide greater accuracy for significance tests, particularly for small samples (Gonçalves \& White, 2005), and therefore 500 bootstraps were used to generate standard error estimates in the current models.

Results of the first model indicate that there were no significant indirect effects of sleep on math development when mediated by self-regulation (Table 6). Self-regulation development was not significantly predicted by sleep quantity $(B=.81, S E=1.88, \beta=.03$, $p=.67)$, latency $(B=.09, S E=2.12, \beta=.00, p=.97)$, disruption $(B=.56, S E=3.05, \beta=.01$, $p=.18)$, or difficulty waking $(B=-.57, S E=.85, \beta=-.03, p=.76)$, even though development of self-regulation significantly predicted development of math skills $(B=.22, S E=.06$, $\beta=.25, p<.001$ ) when controlling for baseline math scores and child and family characteristics.

Results of the second model are similar: there were no significant indirect effects of sleep on literacy development when mediated by self-regulation (Table 6). Development of literacy skills was significantly predicted by development of selfregulation when controlling for baseline literacy scores and child and family characteristics $(B=.30, S E=.13, \beta=.15, p<.01)$, but self-regulation was not significantly predicted by sleep quantity $(B=-2.29, S E=2.97, \beta=-.05 p=.44)$, latency $(B=.83, S E=$ $2.31, \beta=.02, p=.72)$, disruption $(B=-3.50, S E=4.24, \beta=-.04, p=.41)$, or difficulty waking $(B=-.60, S E=1.80, \beta=-.03, p=.74)$.

The relative indirect effects, which loosely represent the proportion of the total effect that is mediated, are presented in Table 6. Overall, they indicate that mediation via 
self-regulation accounts for a very small proportion of the overall association between sleep and academic development. There are two exceptions: the indirect effect of sleep quality on math development through self-regulation explains $89 \%$ of the total association, and the indirect effect of difficulty waking on math development through self-regulation explains $47 \%$ of the total association. These cannot be interpreted as meaningful, however, because a large percentage of a tiny association still represents a very small effect and these effects are not statistically significantly distinguishable from zero.

Taken together, these results fail to support the hypothesized mediation of development of self-regulation on the relation between children's sleep and their development of academic skills. 


\section{Chapter 6: Discussion}

This study examined the role of sleep quality and sleep quantity in young children's development of two school-related skills: academic abilities and selfregulation. The study extends current knowledge about sleep processes in an economically disadvantaged, black population and can contribute to theory that links sleep with underlying biological processes of self-regulation.

\section{Discussion of Findings}

Three sets of research questions were posed to examine: 1) the relation between children's sleep quantity and quality and their development of literacy, math, and selfregulation; 2) differences in this relation between children in kindergarten and $1^{\text {st }}$ grade; and 3) self-regulation as potential mediator of the pathway between sleep and academic development. Results for each set of questions are discussed below.

Main effects. It was hypothesized that children who get more and higher quality sleep would demonstrate greater development of mathematics, literacy, and selfregulation over one calendar year (Hypotheses 1a, 1b, 3a, 3b). Multiple regression analyses were conducted to test whether sleep quantity, sleep latency, sleep disruption, and difficulty waking were associated with children's development of math, literacy, and self-regulation skills when controlling for baseline scores and child and family characteristics. No significant main effects were found for math or self-regulation, even though sleep latency was significantly correlated with self-regulation at baseline $(r=-.18$, $p<.05)$. Literacy development was significantly predicted by difficulty waking, but not 
by any of the other sleep variables. This indicates that children who struggle to wake up in the morning show less development of literacy skills across a calendar year, and thus that this aspect poor quality sleep can be detrimental to children's school success. This is in keeping with Dewald and colleagues' (2010) finding that daytime sleepiness was associated with academic outcomes.

Moderated effects by grade. It was further hypothesized that the positive associations between sleep quantity and sleep quality and children's development of math, literacy, and self-regulation skills would be relatively stronger among kindergarteners than 1st graders (Hypotheses 2a, 2b, 4a, 4b). Results of moderated multiple regression analyses reveal that sleep did not differentially relate to academic development for kindergarteners and first graders. These results do not support Hypothesis 2, as there were no statistically significant differences between the two grades in how sleep related to math and literacy development (see Table 3), and therefore do not replicate the findings of other studies in which older children required more sleep for maximum daytime functioning and academic development (Astill et al, 2012). This may be a result of the close age-range of kindergarteners and first graders in the sample compared with prior studies that included a larger range of ages in their sample (Astill et al, 2012).

A trend toward moderation did emerge in the association between kindergarteners' and $1^{\text {st }}$ graders' sleep and their development of self-regulation; however, these results demonstrate an unexpected pattern that is contrary to Hypothesis 4. At a level approaching statistical significance, the relation between sleep latency and self- 
regulation development was negative for $1^{\text {st }}$ graders $(B=3.94, p=.10)$ but positive for kindergarteners $(B=-3.69, p=.13)$. The results indicate that a kindergartener who takes 15 minutes or fewer to fall asleep will score 8 points lower than one who falls asleep in 45 minutes or longer, whereas a $1^{\text {st }}$ grader who falls asleep quickly will score 10 points higher than one who takes a long time. Although severe sleep latency only affects very few children (5 kindergarteners and $51^{\text {st }}$ graders) and close to $60 \%$ of both kindergarteners and $1^{\text {st }}$ graders in this sample fall asleep within 15 minutes, this pattern nonetheless shows a potentially meaningful difference for the few students who struggle to fall asleep, the implications of which may change dramatically depending on their grade.

One possible explanation lies in the underlying causes of sleep latency as a construct: taking a long time to fall asleep could indicate dysregulation of sleep-wake processes or simply that a child isn't tired by bedtime. Kindergarteners who lie awake in bed may have less taxing school experiences, leaving them less exhausted at the end of the day. Moreover, features of the school environment that could make it less taxing (e.g. fewer instructional demands, minimal classroom chaos) may actually support children's self-regulatory development by creating a more conducive environment in which to practice their regulatory skills (Ursache, Blair \& Raver, 2012). Sleep latency and difficulty waking are only moderately correlated $(r=.27, p<0.01)$, which could be evidence that exhaustion is a relevant factor for some children but not others. However, for this explanation to fit the results shown here, $1^{\text {st }}$ graders' sleep latency would need to be indicative of an underlying cause that became activated by features of the $1^{\text {st }}$ grade 
classroom that weren't present in kindergarten. Further research is needed to replicate and explain these findings; such endeavors could include testing the above theory with more precise measures of self-regulation, more frequent measurement occasions, and examination of the classroom context, or using person-centered analyses of children for whom severe sleep latency is a problem to describe and examine their specific experiences.

Mediated effects through self-regulation. It was hypothesized that the effects of sleep quality and quantity on children's development of math and literacy skills across a calendar year would be significantly but partially explained by the relation between their development of self-regulation and of academic skills (hypotheses 5a, 5b). Results failed to support any mediational models, as associations between sleep characteristics and children's development of self-regulatory skills were not demonstrated by the data. One reason for this finding may be that the measures utilized here were not sensitive enough to capture a relation between sleep and self-regulation, as discussed below.

\section{Limitations}

Measures. The current study has a number of measurement limitations. First and foremost, the sleep measures utilized are not robust. All sleep data come from parents' reports of 'a typical school night' at a single time point, rather than physiological measures of children's nightly sleep over a set period of time. Thus the study relies on a few assumptions about children's sleep and parent's reports. Firstly, it is assumed that children's sleep tendencies will remain stable across a calendar year. This may not be the case, especially given that the bivariate associations between sleep and baseline school- 
related skills show a different pattern than those at Time 2. Secondly, it is assumed in the present study that parent reports are accurate representations of how children tend to sleep throughout the school year. However, parents may not accurately report characteristics of children's sleep, which may reduce reliability of the four sleep measures and attenuate the associations between sleep and children's development. Sleep quantity is calculated from parent reports of average, school-night bedtimes and wake-times, rather than a direct measure of time spent asleep, which may be less accurate if they are being interviewed during the summer. This is more likely to result in smaller effect sizes than studies that measure actual sleep time using more precise measurement tools (Astill et al, 2012). Likewise, parents tend to underestimate night-wakings as compared to actigraphy, which may explain why night-wakings were much less prevalent in this sample than in previous studies (Tikotsky \& Sadeh, 2001). That the relative insensitivity of the measure to capturing children's actual sleep disruptions could attenuate results bolsters the present finding — albeit at trend level—that relations between sleep disruption and math and literacy development are differential for kindergarteners and $1^{\text {st }}$ graders. In a similar vein, parents may be unaware of how long it takes children to fall asleep and thus may be inaccurate in their reports of sleep latency; that trend-level results in which grade moderates the association between sleep latency and self-regulation development are detectable speaks to the relative strength of this finding.

Interestingly, difficulty waking was the only sleep characteristic for which a statistically significant main effect (on literacy development) was found. As 
operationalized in the current study, difficulty waking is an account of a parent's joint experience with their child, rather than their child's isolated or internal experience. Thus, it may be that parents are better able to accurately report how difficult it is "to get [their] child up in the morning" compared to other sleep characteristics, and therefore that the increased sensitivity of the measure made it possible to detect an association between difficulty waking and literacy development.

Moreover, sleep quality was operationalized as three separate items that represent conceptually distinct characteristics of a child's sleep. Rather than using a single sleep quality factor with three indicators, the trifold operationalization in this study necessitated a large number of statistical tests, which can increase the Type II error rate. Although this strategy offers greater specificity into the relations between each sleep characteristic and each developmental outcome, future studies could operationalize sleep quality unitarily. Sleep latency, sleep disruption, and difficulty waking could be considered different ways of getting poor quality sleep and thus aggregated onto a shared scale; this would allow researchers to account for the potentially compounding effect of experiencing multiple sleep problems, which may be more problematic for young children in school than any single sleep problem uniquely. Such analyses may better reflect the actual experiences of young children, and may therefore have more conclusive relations to their academic and regulatory development.

A second main limitation of the measures concerns operationalizing selfregulation with a single behavioral task. As discussed previously, self-regulation is a multi-faceted construct, and accordingly, many direct assessments and report measures 
exist for capturing different aspects of a child's regulatory capacity (Gagne, 2017).

Although the measure used in the current study has been shown to reliably and validly capture children's behavioral self-regulation (McClelland et al, 2014), there was a floor effect in the sample that may have attenuated results. This one-dimensional operationalization of self-regulation may explain why the hypothesized the pathway in which self-regulation mediated the relation between sleep and children's development of academic skills was not borne out in the data. Future research should include multiple measures of self-regulation, including executive function and behavioral measures, so as to best evaluate how sleep and self-regulation work together in young children at school.

Finally, this study did not directly test the theories on which some of the research questions are based. Specifically, the relation between sleep-loss stress, arousal, selfregulation and academic performance cannot be tested directly with the available methodology, since the study does not use an experimental design or use physiological measures. This is a common limitation in secondary data analysis: the study from which this data is drawn was not originally intended to evaluate the research questions posed here. Regardless, this study can be seen as a first step towards shedding light on how sleep, self-regulation, and academic skills develop synergistically, and can thus provide guidance for future research on this topic.

Sample. In addition to limitations of the measures used in this study, there are both benefits and disadvantages of studying a unique and homogenous sample such as the one studied here. Participants in this sample are almost entirely black and economically disadvantaged, two traditional risk factors for success across the school transition. 
Understanding the nature of sleep and school readiness for these children may elucidate points of leverage through which to mitigate achievement gaps, beyond simply measuring how and where these gaps exist. Prior research suggests that sleep patterns of AfricanAmerican children are different than those of European-American children, although the homogeneity of the current sample precludes a meaningful comparison to children from different backgrounds and environments for whom the mechanisms of sleep and school success may work differently. The obvious disadvantage of the homogenous sample with regards to generalizability between populations is offset by clearer generalizability to similar subpopulations (Jager, Putnick \& Bornstein, 2017). In this context, such research may be useful for researchers working to improve the lives of impoverished, AfricanAmerican children. Given the racial and economic disparities in both sleep and school success described previously, the work presented here can serve as a foundation for future endeavors to mitigate these gaps.

\section{Implications for Research and Practice}

This research has the potential to make valuable contributions to the study of childhood sleep and the study of school readiness. As previously discussed, experts have explicitly called for more sleep research among children in pre-k through 3rd grade, among children from racially and socioeconomically diverse backgrounds, and utilizing longitudinal designs (El Sheikh, 2011). The current study includes descriptive data about sleep in these populations, and uses a longitudinal design to address its role in development. These descriptive analyses contribute to this growing body of work and may be informative for researchers studying sleep habits among young children. 
In addition to contributing to the field of sleep research specifically, this study extends our understanding of sleep's role in academic development. Much school readiness literature addresses the skills and environments that facilitate success at school entry, but understanding where sleep fits in this context may help to clarify the connection between biological phenomena and development of such skills. One striking finding is that sleep relates differentially to different school-related outcomes. Results did not show a consistent, positive relation between good sleep and academic growth; instead only one measure (difficulty waking) was significantly associated with development in one school domain (literacy). Moreover, $1^{\text {st }}$ graders who take longer to fall asleep exhibit less self-regulatory growth than their peers while similar kindergarteners exhibit more self-regulatory growth than their peers. These unexpected findings underscore the importance of embedding investigations of sleep and academic development in the real contexts young children experience. Although school-related outcomes are highly correlated, the developmental processes that lead to success in these domains may have different trajectories, timelines, and mechanisms, and the multifaceted dynamics of sleep may have unique and varied implications. This is a ripe topic for school readiness researchers to incorporate physiological data and longitudinal designs to understand the underlying mechanisms that contribute to both to sleep difficulties and to the development of crucial school-related skills.

A more in-depth understanding of sleep promotion and sleep's role in school readiness can provide actionable information for caregivers and for educators. Metaanalytic studies demonstrate the efficacy of behavioral interventions for pediatric 
insomnia (Meltzer \& Mindell, 2014), and multiple effective strategies have been examined, as described by Sadeh (2005). Graduated extinction — in which the reinforcing stimulus of parental interaction is removed after bedtime - has been effective in multiple clinical studies for minimizing problems settling down after bedtime and is a fairly intuitive and easily implemented strategy for parents. Alternatively, parents can employ a 'faded bedtime' technique by allowing their child's bedtime to more closely match his or her natural sleep patterns in addition to establishing calming and enjoyable bedtime routines; after this point bedtimes can be gradually pushed earlier as needed. In addition to the above methods, combining multiple strategies has been effective in helping children fall asleep more easily. Such behavioral and cognitive interventions involve both changing parents' behavior towards their child's sleep as well as changing their perceptions and expectations, and therefore strategies that are easy for parents to understand and implement can often be more effective. Accordingly, parent education can be crucial for children with moderate sleep difficulties (Sadeh, 2005).

With a solid understanding of the importance of sleep and how it can affect children at schoool, teachers and parents can work together to utilize this information to assist individual children. Such knowledge can provide a lens through which to better understand problems that individual children have in school and vulnerabilities that parents and educators can work to counteract. The two main findings of the current study — that difficulty waking hinders early literacy and that sleep latency may have implications for self-regulatory development—regard detectable problems that parents and teachers can work to mitigate. If teachers notice that a child is having academic 
difficulty, they can alert parents to observe how sleep may be a potentially aggravating factor; likewise, parents can inform teachers of the difficulties children have at home so as to allow them to better address those children's needs in the classroom. Similarly, teachers and parents can support each other in recognizing the signs of sleep-loss stress (Weissbluth, 1989), which otherwise may be interpreted as signs of larger behavioral problems.

In addition to addressing sleep so as to facilitate school success, schools can be a crucial avenue through which to promote good sleep. Studies show that early schoolbased screening not only can mitigate sleep problems but also can impact children's prosocial behavior within their first year of school (Quach, Hiscock, Ukoumunne, \& Wake, 2011). A parent education program administered through Head Start was also shown to significantly increase low-income preschoolers' nighttime sleep (Wilson, Miller, Bonuck, Lumeng \& Chervin, 2014). Therefore, increasing parents and teachers' knowledge about sleep and sleep problems can be an effective way to direct support towards children who need them.

The present study does not provide specific recommendations for those who care for young children, but it demonstrates that sleep relates to children's development in ways that affect their experiences at school and warrant further exploration. Working to give parents and educators the tools they need to support and improve children's sleep may, therefore, be a useful intervention strategy for improving at-risk children's transition to school. 


\section{References}

Ackerman, B. P., \& Brown, E. D. (2011). The ecology of economic disadvantage and children's sleep. In M. El-Sheikh (Ed.), Sleep and development: Familial and socio-cultural considerations, (pp. 301-32). New York, NY: Oxford.

Astill, R. G., Van der Heijden, K. B., Van Ijzendoorn, M. H., \& Van Someren, E. J. (2012). Sleep, cognition, and behavioral problems in school-age children: A century of research meta-analyzed. Psychological Bulletin, 138(6), 1109.

Baron, R. M., \& Kenny, D. A. (1986). The moderator-mediator variable distinction in social psychological research: Conceptual, strategic, and statistical considerations. Journal of personality and social psychology, 51(6), 1173.

Baumeister, R. F. (2002). Ego Depletion and Self-Control Failure: An Energy Model of the Self's Executive Function. Self and Identity, 1(2), 129-136. https://doi.org/10.1080/152988602317319302

Baumeister, R. F., \& Vohs, K. D. (2007). Self-Regulation, Ego Depletion, and Motivation. Social and Personality Psychology Compass, 1(1), 115-128. https://doi.org/10.1111/j.1751-9004.2007.00001.x

Bassok, D., Latham, S., \& Rorem, A. (2016). Is kindergarten the new first grade?. AERA Open, 2(1), 2332858415616358.

Bassok, D., Gibbs, C. R., \& Latham, S. (2015). Do the Benefits of Early Childhood Interventions Systematically Fade? Exploring Variation in the Association Between Preschool Participation and Early School Outcomes. EdPolicyWorks 
Working Paper. Retrieved from:

http://curry.virginia.edu/uploads/resourceLibrary/36_Preschool_Fade_Out.pdf

Bates, J. E., Viken, R. J., Alexander, D. B., Beyers, J., \& Stockton, L. (2002). Sleep and Adjustment in Preschool Children: Sleep Diary Reports by Mothers Relate to Behavior Reports by Teachers. Child Development, 73(1), 62.

Beebe, D. W. (2011). Cognitive, behavioral, and functional consequences of inadequate sleep in children and adolescents. Pediatric Clinics of North America, 58(3), 649665.

Blair, C. (2002). School readiness: Integrating cognition and emotion in a neurobiological conceptualization of children's functioning at school entry. American psychologist, 57(2), 111-127.

Blair, C., \& Diamond, A. (2008). Biological processes in prevention and intervention: The promotion of self-regulation as a means of preventing school failure. Development and Psychopathology, 20(3), 899-911. http://doi.org/10.1017/S0954579408000436

Blair, C., \& Raver, C. C. (2012). Child development in the context of adversity: Experiential canalization of brain and behavior. American Psychologist, 67(4), 309-318. https://doi.org/http://dx.doi.org.proxy.lib.pdx.edu/10.1037/a0027493

Blair, C., \& Raver, C. C. (2015). School readiness and self-regulation: A developmental psychobiological approach. Annual review of psychology, 66, 711-731.

Blair, C., Raver, C. C., Granger, D., Mills-Koonce, R., Hibel, L., \& Family Life Project Key Investigators. (2011). Allostasis and allostatic load in the context of poverty 
in early childhood. Development and Psychopathology, 23(3), 845-857. https://doi.org/10.1017/S0954579411000344

Blair, C., \& Razza, R. P. (2007). Relating effortful control, executive function, and false belief understanding to emerging math and literacy ability in kindergarten. Child development, 78(2), 647-663.

Blair, C., \& Ursache, A. (2011). A bidirectional theory of executive functions and selfregulation. In K. Vohs, \& R. Baumeister (Eds.), Handbook of self-regulation (2 ed., pp. 300-320). New York: Guilford Press.

Borbély, A. A., Daan, S., Wirz-Justice, A., \& Deboer, T. (2016). The two-process model of sleep regulation: a reappraisal. Journal of Sleep Research, 25(2), 131-143. https://doi.org/10.1111/jsr.12371

Brown, E. D., \& Low, C. M. (2008). Chaotic living conditions and sleep problems associated with children's responses to academic challenge. Journal of Family Psychology, 22(6), 920-923. https://doi.org/http://dx.doi.org.proxy.lib.pdx.edu/10.1037/a0013652

Bub, K. L., Robinson, L. E., \& Curtis, D. S. (2016). Longitudinal associations between self-regulation and health across childhood and adolescence. Health Psychology, $35(11), 1235-1245$. https://doi.org/http://dx.doi.org.proxy.lib.pdx.edu/10.1037/hea0000401

Buckhalt, J.A., El-Sheikh, M., \& Keller, P. (2007). Children's sleep and cognitive functioning: Race and socioeconomic status as moderators of effects. Child development, 78(1), 213-231. 
Buckhalt, J.A., El-Sheikh, M., Keller, P., \& Kelly, R.J. (2009). Concurrent and longitudinal relations between children's sleep and cognitive functioning: The moderating role of parent education. Child development, 80(3), 875-892.

Buckhalt, J. A., \& Staton, L. E. (2011). Children's sleep, cognition, and academic performance in the context of socioeconomic status and ethnicity. In M. ElSheikh (Ed.), Sleep and development: Familial and socio-cultural considerations, (pp. 245-264). New York, NY: Oxford.

Cairns, A., \& Harsh, J. (2014). Changes in Sleep Duration, Timing, and Quality as Children Transition to Kindergarten. Behavioral Sleep Medicine, 12(6), 507-516. https://doi.org/10.1080/15402002.2013.838765

Carskadon, M., Dement, W. (2005) Normal human sleep: An overview. In: Kryger, M.H., Roth, T., Dement, W.C., (Eds), Principles and Practice of Sleep Medicine (4th ed) (pp. 13-23). Philadelphia, PA: Elsevier Saunders.

Cohen, J. (1988). Statistical power analyses for the social sciences. Hillsdale, NJ, Lawrence Erlbauni Associates.

Colten, H.R. \& Altevogt, B.M. (Eds.). (2006). Sleep Disorders and Sleep Deprivation: An Unmet Public Health Problem. Washington, DC: National Academies Press. Available from: https://www.ncbi.nlm.nih.gov/books/NBK19956/

Crosby, B., LeBourgeois, M. K., \& Harsh, J. (2005). Racial Differences in Reported Napping and Nocturnal Sleep in 2- to 8-Year-Old Children. Pediatrics, 115(1 Suppl), 225-232. https://doi.org/10.1542/peds.2004-0815D 
Dahl, R. E. (1996a). The regulation of sleep and arousal. Development and Psychopathology, 8(1), 3-27. https://doi.org/10.1017/S0954579400006945

Dahl, R. E. (1996b). The impact of inadequate sleep on children's daytime cognitive function. Seminars in Pediatric Neurology, 3(1), 44-50. https://doi.org/10.1016/S1071-9091(96)80028-3

Dahl, R.E. (2011) Foreward. In M. El-Sheikh (Ed.), Sleep and development: Familial and socio-cultural considerations, (pp. vii-x). New York, NY: Oxford.

Dean, R.S. (2011) Woodcock Johnson-III Tests of Achievement. In S. Goldstein \& J.A. Naglieri (Eds.) Encyclopedia of Child Behavior and Development, (pp. 15751576) New York, NY: Springer.

Dewald, J. F., Meijer, A. M., Oort, F. J., Kerkhof, G. A., \& Bögels, S. M. (2010). The influence of sleep quality, sleep duration and sleepiness on school performance in children and adolescents: a meta-analytic review. Sleep Medicine Reviews, 14(3), $179-189$.

Diaz, A., Berger, R., Valiente, C., Eisenberg, N., VanSchyndel, S. K., Tao, C., ... \& Southworth, J. (2016). Children's sleep and academic achievement: The moderating role of effortful control. International Journal of Behavioral Development, 1-10. DOI:0165025416635284.

Duncan, G. J., Dowsett, C. J., Claessens, A., Magnuson, K., Huston, A. C., Klebanov, P., . . Japel, C. (2007). School readiness and later achievement. Developmental Psychology, 43(6), 1428-1446. Retrieved from 
http://stats.lib.pdx.edu/proxy.php?url=http://search.proquest.com.proxy.lib.pdx.ed $\mathrm{u} /$ docview/614471962?accountid=13265

Eisenberg, N., Valiente, C., \& Eggum, N. D. (2010). Self-regulation and school readiness. Early Education and Development, 21(5), 681-698.

El-Sheikh, M. (2011) Introduction and overview: Salient issues in the consideration of sleep in context. In M. El-Sheikh (Ed.) Sleep and development: Familial and socio-cultural considerations, (pp. xi-xvi). New York, NY: Oxford.

El-Sheikh, M., Bagley, E. J., Keiley, M., Elmore-Staton, L., Chen, E., \& Buckhalt, J. A. (2013). Economic adversity and children's sleep problems: Multiple indicators and moderation of effects. Health Psychology, 32(8), 849-859. https://doi.org/http://dx.doi.org.proxy.lib.pdx.edu/10.1037/a0030413

Enders, C.K. (2013) Analyzing structural equation models with missing data. In G.R. Hanckock \& R.O. Mueller (Eds.) Structural equation modeling: A second course $2^{\text {nd }}$ ed. (pp. 493-520). Charlotte, NC: Information Age Publishing.

Enders, C. K. (2001). The performance of the full information maximum likelihood estimator in multiple regression models with missing data. Educational and Psychological Measurement, 61(5), 713-740.

Evans, G. W. (2004). The Environment of Childhood Poverty. American Psychologist, 59(2), 77-92. https://doi.org/http://dx.doi.org.proxy.lib.pdx.edu/10.1037/0003066X.59.2.77 
Evans, G. W., \& Kim, P. (2013). Childhood Poverty, Chronic Stress, Self-Regulation, and Coping. Child Development Perspectives, 7(1), 43-48. https://doi.org/10.1111/cdep.12013

Fallone, G., Acebo, C., Seifer, R., \& Carskadon, M. A. (2005). Experimental restriction of sleep opportunity in children: effects on teacher ratings. SLEEP, 28(12), 1561.

Gagne, J. R. (2017). SelfControl in Childhood: A Synthesis of Perspectives and Focus on Early Development. Child Development Perspectives, 11(2), 127-132.

Galland, B. C., Taylor, B. J., Elder, D. E., \& Herbison, P. (2012). Normal sleep patterns in infants and children: A systematic review of observational studies. Sleep Medicine Reviews, 16(3), 213-222. https://doi.org/10.1016/j.smrv.2011.06.001

Gellis, L.A. (2011). Children's sleep in the context of race, socioeconomic status, and ethnicity. In M. El-Sheikh (Ed.), Sleep and development: Familial and sociocultural considerations, (pp. 219-244). New York, NY: Oxford.

Grandner, M. A., Petrov, M. E. R., Rattanaumpawan, P., Jackson, N., Platt, A., \& Patel, N. P. (2013). Sleep Symptoms, Race/Ethnicity, and Socioeconomic Position. Journal of Clinical Sleep Medicine : JCSM : Official Publication of the American Academy of Sleep Medicine, 9(9), 897-905. https://doi.org/10.5664/jcsm.2990

Gonçalves, S., \& White, H. (2005). Bootstrap standard error estimates for linear regression. Journal of the American Statistical Association, 100(471), 970-979.

Howse, R. B., Calkins, S. D., Anastopoulos, A. D., Keane, S. P., \& Shelton, T. L. (2003). Regulatory contributors to children's kindergarten achievement. Early Education and Development, 14(1), 101-120. 
Jager, J., Putnick, D. L., \& Bornstein, M. H. (2017). II. MORE THAN JUST

CONVENIENT: THE SCIENTIFIC MERITS OF HOMOGENEOUS

CONVENIENCE SAMPLES. Monographs of the Society for Research in Child

Development, 82(2), 13-30.

Liu, J., Zhou, G., Wang, Y., Ai, Y., Pinto-Martin, J., \& Liu, X. (2012). Sleep Problems, Fatigue, and Cognitive Performance in Chinese Kindergarten Children. The Journal of Pediatrics, 161(3), 520-525.e2. https://doi.org/10.1016/j.jpeds.2012.03.018

Magnuson, K. A., Meyers, M. K., Ruhm, C. J., \& Waldfogel, J. (2004). Inequality in preschool education and school readiness. American educational research journal, 4l(1), 115-157.

Matthews, J. S., Ponitz, C. C., \& Morrison, F. J. (2009). Early gender differences in selfregulation and academic achievement. Journal of Educational Psychology, 101(3), 689.

McClelland, M. M., Acock, A. C., \& Morrison, F. J. (2006). The impact of kindergarten learning-related skills on academic trajectories at the end of elementary school. Early Childhood Research Quarterly, 21(4), 471-490.

https://doi.org/10.1016/j.ecresq.2006.09.003

McClelland, M. M., Cameron, C. E., Duncan, R., Bowles, R. P., Acock, A. C., Miao, A., \& Pratt, M. E. (2014). Predictors of early growth in academic achievement: The head-toes-knees-shoulders task. Frontiers in Psychology, 5, 599. http://doi.org/10.3389/fpsyg.2014.00599 
McLaughlin Crabtree, V., Beal Korhonen, J., Montgomery-Downs, H. E., Faye Jones, V., O’Brien, L. M., \& Gozal, D. (2005). Cultural influences on the bedtime behaviors of young children. Sleep Medicine, 6(4), 319-324.

https://doi.org/10.1016/j.sleep.2005.02.001

Meijer, Habekothé, Van Den Wittenboer, \& Meijer. (2000). Time in bed, quality of sleep and school functioning of children. Journal of Sleep Research, 9(2), 145-153.

Meltzer, L.J., \& Mindell, J.A. (2014). Systematic review and meta-analysis of behavioral interventions for pediatric insomnia. Journal of Pediatric Psychology 39(8), 932948, 2014.

Molfese, V. J., Rudasill, K. M., \& Molfese, D. L. (2013). Sleep in Preschoolers: School Readiness, Academics, Temperament, and Behavior. The Oxford Handbook of Infant, Child, and Adolescent Sleep and Behavior, (pp. 397-413). New York, NY: Oxford University Press.

Montgomery-Downs, H. E., Jones, V. F., Molfese, V. J., \& Gozal, D. (2003). Snoring in preschoolers: associations with sleepiness, ethnicity, and learning. Clinical Pediatrics, 42(8), 719-726.

NAEYC (2009). Where we stand on school readiness. National Association for the Education of Young Children. Retrieved from https://www.naeyc.org/positionstatements/school_readiness.

O'Brien, L. M. (2013). Neurocognitive implications. In The Oxford Handbook of Infant, Child, and Adolescent Sleep and Behavior (p. 414). New York, NY: Oxford University Press. 
Ohayon, M. M., Carskadon, M. A., Guilleminault, C., \& Vitiello, M. V. (2004). Metaanalysis of quantitative sleep parameters from childhood to old age in health individuals: Developing normative sleep values across the human lifespan. ResearchGate, 27(7), 1255-73.

Owens, J. A. (2004). Sleep in children: Cross-cultural perspectives. Sleep and Biological Rhythms, 2(3), 165-173. https://doi.org/10.1111/j.1479-8425.2004.00147.x

Paruthi, S., Brooks, L. J., D’Ambrosio, C., Hall, W. A., Kotagal, S., Lloyd, R. M., ... \& Rosen, C. L. (2016). Recommended amount of sleep for pediatric populations: a consensus statement of the American Academy of Sleep Medicine. J Clin Sleep Med, 12(6), 785-786.

Ponitz, C. C., Rimm-Kaufman, S. E., Grimm, K. J., \& Curby, T. W. (2009). Kindergarten classroom quality, behavioral engagement, and reading achievement. School Psychology Review, 38(1), 102-120.

Quach, J., Hiscock, H., Ukoumunne, O. C., \& Wake, M. (2011). A brief sleep intervention improves outcomes in the school entry year: a randomized controlled trial. Pediatrics, 128(4), 692-701.

Reardon, S. F. (2011). The widening academic achievement gap between the rich and the poor: New evidence and possible explanations. Whither opportunity, 91-116.

Rimm-Kaufman, S. E., Curby, T. W., Grimm, K. J., Nathanson, L., \& Brock, L. L. (2009). The contribution of children's self-regulation and classroom quality to children's adaptive behaviors in the kindergarten classroom. Developmental psychology, 45(4), 958. 
Rothbart, M.K., Ellis, L.K. \& Posner, M.I. (2004). Temperament and self regulation. In R.F. Baumeister \& K.D. Vohs (eds.), Handbook of Self Regulation. (pp. 357-370) New York, NY: Guilford Press.

Rosseel, Y. (2012). lavaan: An R Package for Structural Equation Modeling. Journal of Statistical Software, 48(2), 1-36. URL http://www.jstatsoft.org/v48/i02/.

Rucker, D. D., Preacher, K. J., Tormala, Z. L., \& Petty, R. E. (2011). Mediation analysis in social psychology: Current practices and new recommendations. Social and Personality Psychology Compass, 5(6), 359-371.

Ryan, R. M., Fauth, R. C., \& Brooks-Gunn, J. (2006). Childhood Poverty: Implications for School Readiness and Early Childhood Education. In B. Spodek \& O. N. Saracho (Eds.), Handbook of research on the education of young children, 2nd ed (pp. 323-346). Mahwah, NJ, US: Lawrence Erlbaum Associates Publishers.

Sabol, T. J., \& Pianta, R. C. (2012). Patterns of school readiness forecast achievement and socioemotional development at the end of elementary school. Child development, 83(1), 282-299.

Sadeh, A. (2011). Sleep Assessment Methods. In M. El-Sheikh (Ed.), Sleep and development: Familial and socio-cultural considerations, (pp. 355-374). New York, NY: Oxford.

Sadeh, A. (2005). Cognitive-behavioral treatment for childhood sleep disorders. Clinical psychology review, 25(5), 612-628.

Sadeh, A., Raviv, A., \& Gruber, R. (2000). Sleep patterns and sleep disruptions in school-age children. Developmental Psychology, 36(3), 291-301. 
Scher, A., Hall, W. A., Zaidman-Zait, A., \& Weinberg, J. (2010). Sleep Quality, Cortisol Levels, and Behavioral Regulation in Toddlers. Developmental Psychobiology, 52(1), 44-53. https://doi.org/10.1002/dev.20410

Tikotzky, L., \& Sadeh, A. (2001). Sleep Patterns and Sleep Disruptions in Kindergarten Children. Journal of Clinical Child Psychology, 30(4), 581-591.

Touchette, É., Petit, D., Séguin, J. R., Boivin, M., Tremblay, R. E., \& Montplaisir, J. Y. (2007). Associations Between Sleep Duration Patterns and Behavioral/Cognitive Functioning at School Entry. Sleep, 30(9), 1213-1219.

Ursache, A., Blair, C., \& Raver, C. C. (2012). The promotion of self-regulation as a means of enhancing school readiness and early achievement in children at risk for school failure. Child Development Perspectives, 6(2), 122-128.

Vaughn, B. E., Elmore-Staton, L., Shin, N., \& El-Sheikh, M. (2015). Sleep as a support for social competence, peer relations, and cognitive functioning in preschool children. Behavioral Sleep Medicine, 13(2), 92-106. https://doi.org/http://dx.doi.org.proxy.lib.pdx.edu/10.1080/15402002.2013.84577 8

Weissbluth, M. (1989). Sleep-loss stress and temperamental difficultness: Psychobiological processes and practical considerations. In G. A. Kohnstamm, J. E. Bates, \& M. K. Rothbart (Eds.), Temperament in childhood (pp. 357-375). Oxford, England: John Wiley \& Sons.

Welsh, J. A., Nix, R. L., Blair, C., Bierman, K. L., \& Nelson, K. E. (2010). The development of cognitive skills and gains in academic school readiness for 
SLEEP AND CHILDREN'S DEVELOPMENT

children from low-income families. Journal of Educational Psychology, 102(1), 43-53. https://doi.org/http://dx.doi.org.proxy.lib.pdx.edu/10.1037/a0016738

Williams, K.E., Berthelsen, D., Walker, S., \& Nicholson, J.M. (2017). A developmental cascade model of behavioral sleep problems and emotional and attentional selfregulation across early childhood. Behavioral Sleep Medicine, 15(1): 1-21. doi: $10.1080 / 15402002.2015 .1065410$

Williams, K.E., Nicholson, J.M., Walker, S., \& Berthelsen, D. (2016) Early childhood profiles of sleep problems and self-regulation predict later school adjustment. British Journal of Educational Psychology, 86(2): 331-50. doi:10.1111/bjep.12109.

Williams, K. E., \& Sciberras, E. (2016). Sleep and self-regulation from birth to 7 years: A retrospective study of children with and without attention-deficit hyperactivity disorder at 8 to 9 years. Journal of Developmental \& Behavioral Pediatrics, 37(5), 385-394.

Wilson, K. E., Miller, A. L., Bonuck, K., Lumeng, J. C., \& Chervin, R. D. (2014). Evaluation of a sleep education program for low-income preschool children and their families. Sleep, 37(6), 1117-1125.

WINGS for Kids (2013). WINGS for Kids. Retrieved from http://www.wingsforkids.org.

Yokomaku, A., Misao, K., Omoto, F., Yamagishi, R., Tanaka, K., Takada, K., \& Kohyama, J. (2008). A study of the association between sleep habits and problematic behaviors in preschool children. Chronobiology International, 25(4), $549-564$. 


\section{Appendix A}

\section{Summary of Key Articles}

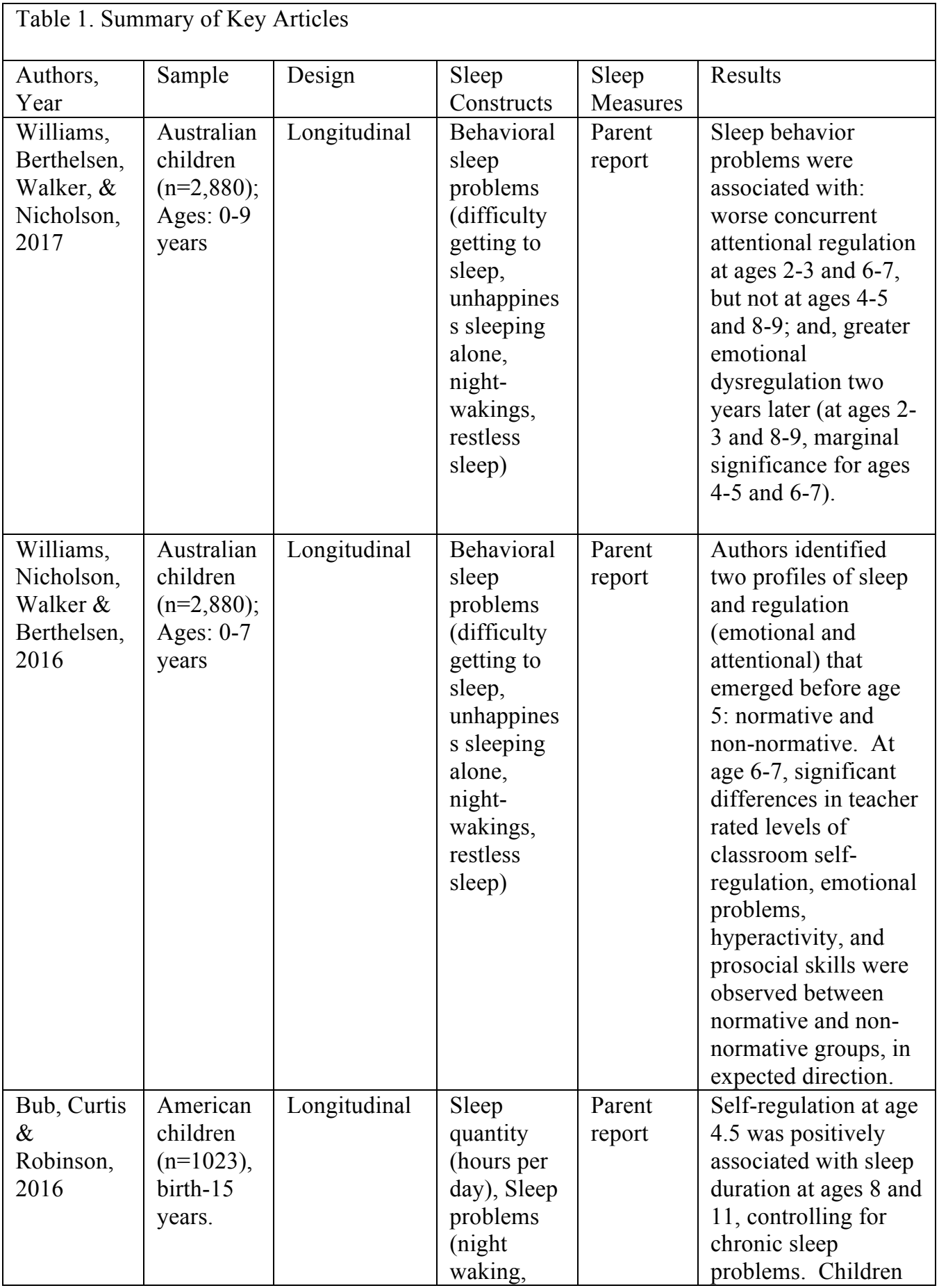




\begin{tabular}{|c|c|c|c|c|c|}
\hline & & & $\begin{array}{l}\text { daytime } \\
\text { sleepiness) }\end{array}$ & & $\begin{array}{l}\text { who exhibited poorer } \\
\text { self-regulation at age } \\
4.5 \text { also had, on } \\
\text { average, more night } \\
\text { wakings and daytime } \\
\text { sleepiness at age } 8 . \\
\text { These results were } \\
\text { less robust at age } 11 \text {, } \\
\text { and disappeared by } \\
\text { age } 15 \text {. }\end{array}$ \\
\hline $\begin{array}{l}\text { Diaz et. al., } \\
2016\end{array}$ & $\begin{array}{l}\text { Kindergar } \\
\text { teners } \\
(\mathrm{n}=103) ; \\
\text { Age: } m= \\
5.98, S D \\
=0.61\end{array}$ & $\begin{array}{l}\text { Cross- } \\
\text { sectional }\end{array}$ & $\begin{array}{l}\text { Duration, } \\
\text { duration } \\
\text { variability, } \\
\text { onset, } \\
\text { latency, } \\
\text { efficiency }\end{array}$ & $\begin{array}{l}\text { Acti- } \\
\text { graphy, } \\
\text { Parent } \\
\text { report }\end{array}$ & $\begin{array}{l}\text { Significant relations } \\
\text { were found between } \\
\text { sleep quality } \\
\text { (duration variability, } \\
\text { onset, latency) and } \\
\text { academic } \\
\text { achievement (as } \\
\text { measured by } \\
\text { Woodcock-Johnson } \\
\text { Applied Problems } \\
\text { and Passage } \\
\text { Comprehension) for } \\
\text { children with low } \\
\text { effortful control } \\
\text { (EC), such that poor } \\
\text { sleep was associated } \\
\text { with poorer academic } \\
\text { performance; these } \\
\text { patterns did not } \\
\text { emerge for children } \\
\text { with high EC. }\end{array}$ \\
\hline $\begin{array}{l}\text { Vaughn, } \\
\text { Elmore- } \\
\text { Staton, } \\
\text { Shin, \& El- } \\
\text { Sheikh, } \\
2015\end{array}$ & $\begin{array}{l}\text { Pre-school } \\
\text { children } \\
(\mathrm{n}=62) ; \\
\text { age: } 4.15 \\
(0.62)\end{array}$ & $\begin{array}{l}\text { Cross- } \\
\text { sectional }\end{array}$ & $\begin{array}{l}\text { Night sleep } \\
\text { duration, } \\
\text { night sleep } \\
\text { efficiency, } \\
\text { night sleep } \\
\text { latency, } \\
\text { variability } \\
\text { of wake } \\
\text { onset }\end{array}$ & $\begin{array}{l}\text { Acti- } \\
\text { graphy }\end{array}$ & $\begin{array}{l}\text { Night sleep duration } \\
\text { was significantly } \\
\text { related to children's } \\
\text { receptive vocabulary. } \\
\text { Sleep duration was } \\
\text { significantly related } \\
\text { to ego resilience and } \\
\text { self-corrections on } \\
\text { the HTKS measure of } \\
\text { behavioral self- } \\
\text { regulation, but not } \\
\text { significantly related } \\
\text { to the overall HTKS } \\
\text { score, teacher ratings } \\
\text { of attention and } \\
\text { focus, or ego } \\
\text { undercontrol. } \\
\text { Variability of wake } \\
\text { onset was also } \\
\text { significantly related } \\
\text { to HTKS self-correct }\end{array}$ \\
\hline
\end{tabular}




\begin{tabular}{|c|c|c|c|c|c|}
\hline & & & & & $\begin{array}{l}\text { and ego- } \\
\text { undercontrol. Sleep } \\
\text { latency and sleep } \\
\text { efficiency showed no } \\
\text { significant relations } \\
\text { with self-regulatory } \\
\text { or cognitive } \\
\text { outcomes. }\end{array}$ \\
\hline $\begin{array}{l}\text { Liu, Zhou, } \\
\text { Wang, Ai, } \\
\text { Pinto- } \\
\text { Martin, } \\
\text { \& Liu, } \\
2012\end{array}$ & $\begin{array}{l}\text { Chinese } \\
\text { Kindergar } \\
\text { teners } \\
(\mathrm{n}=1385) \\
\text { Age: } m= \\
5.72, S D= \\
0.42\end{array}$ & $\begin{array}{l}\text { Cross- } \\
\text { Sectional }\end{array}$ & $\begin{array}{l}\text { Sleep } \\
\text { problems } \\
\text { (difficulty } \\
\text { maintainin } \\
\text { g sleep, } \\
\text { sleep } \\
\text { talking, } \\
\text { sleep } \\
\text { resistance, } \\
\text { nightmares } \\
\text { ); Daytime } \\
\text { fatigue }\end{array}$ & $\begin{array}{l}\text { Parent } \\
\text { report }\end{array}$ & $\begin{array}{l}\text { Children who } \\
\text { exhibited sleep } \\
\text { problems scored, on } \\
\text { average, 2-3 points } \\
\text { lower in full IQ than } \\
\text { children without } \\
\text { sleep problems. } \\
\text { Children who } \\
\text { exhibited daytime } \\
\text { fatigue scored, on } \\
\text { average, 3-6 points } \\
\text { lower in full IQ than } \\
\text { those children } \\
\text { without fatigue. }\end{array}$ \\
\hline $\begin{array}{l}\text { Yokomaku, } \\
\text { Misao, } \\
\text { Omoto, } \\
\text { Yamagishi, } \\
\text { Tanaka, } \\
\text { Takada, \& } \\
\text { Kohyama, } \\
2008\end{array}$ & $\begin{array}{l}\text { Japanese } \\
\text { children } \\
(\mathrm{n}=135), \\
\text { aged } 4-6 .\end{array}$ & $\begin{array}{l}\text { Cross- } \\
\text { sectional }\end{array}$ & $\begin{array}{l}\text { Wake-up } \\
\text { times, } \\
\text { bedtimes, } \\
\text { nocturnal } \\
\text { sleep } \\
\text { duration, } \\
\text { nap } \\
\text { duration, } \\
\text { total sleep } \\
\text { duration, } \\
\text { wake-up } \\
\text { time range, } \\
\text { bedtime } \\
\text { range. }\end{array}$ & $\begin{array}{l}\text { Parent } \\
\text { report }\end{array}$ & $\begin{array}{l}\text { This study of } \\
\text { children who } \\
\text { exhibited frequent } \\
\text { late-bedtime } \\
\text { behaviors suggests } \\
\text { that such children } \\
\text { were more likely to } \\
\text { exhibit behavioral } \\
\text { problems than those } \\
\text { who did not exhibit } \\
\text { frequent late-bedtime } \\
\text { behaviors. Thought } \\
\text { Problems and } \\
\text { Attention Problems } \\
\text { (as measured by the } \\
\text { Child Behavior } \\
\text { Checklist) were } \\
\text { positively and } \\
\text { significantly related } \\
\text { to wake up times and } \\
\text { wake-up time range, } \\
\text { and thought problems } \\
\text { were positively and } \\
\text { significantly related } \\
\text { to nap duration. }\end{array}$ \\
\hline $\begin{array}{l}\text { Touchette, } \\
\text { Petit, } \\
\text { Séguin, } \\
\text { Boivin, } \\
\text { Tremblay } \\
\&\end{array}$ & $\begin{array}{l}\text { Canadian } \\
\text { children } \\
(\mathrm{n}=1492), \\
\text { data } \\
\text { collected } \\
\text { birth-age }\end{array}$ & Longitudinal & $\begin{array}{l}\text { Night sleep } \\
\text { duration, } \\
\text { day sleep } \\
\text { duration, } \\
\text { daytime } \\
\text { sleepiness }\end{array}$ & $\begin{array}{l}\text { Parent } \\
\text { report }\end{array}$ & $\begin{array}{l}\text { Four patterns of sleep } \\
\text { duration emerged } \\
\text { from longitudinal } \\
\text { analyses: short- } \\
\text { persistent (less than } \\
10 \text { hours), short- }\end{array}$ \\
\hline
\end{tabular}




\begin{tabular}{|c|c|c|c|c|c|}
\hline $\begin{array}{l}\text { Montplaisir } \\
\text {, } 2007\end{array}$ & $\begin{array}{l}6, \\
\text { measured } \\
\text { at age } \\
5.1 \pm 0.3 \\
\text { and } \\
6.2 \pm 0.3 \text {. }\end{array}$ & & & & $\begin{array}{l}\text { increasing (less than } \\
10 \text { in early childhood, } \\
\text { increasing by age } \\
3.5-4), 10 \text {-hour } \\
\text { persistent, and 11- } \\
\text { hour persistent. More } \\
\text { children with high } \\
\text { levels of } \\
\text { hyperactivity- } \\
\text { impulsivity were in } \\
\text { the short-increasing } \\
\text { group than the 10- } \\
\text { hour persistent group. } \\
\text { More children in the } \\
\text { short persistent group } \\
\text { had lower receptive } \\
\text { vocabulary scores, a } \\
\text { risk } 3.1 \text { times greater } \\
\text { of lower scores the } \\
11 \text {-hour persistent } \\
\text { group. More children } \\
\text { in the short } \\
\text { increasing group } \\
\text { exhibited lower } \\
\text { nonverbal } \\
\text { intelligence, with the } \\
\text { risk of lower scores } \\
2.4 \text { times greater than } \\
\text { the } 11 \text {-hour persistent } \\
\text { group. Results were } \\
\text { significant, even after } \\
\text { controlling for } \\
\text { potential confounds. }\end{array}$ \\
\hline $\begin{array}{l}\text { Fallone, } \\
\text { Acebo, } \\
\text { Seifer \& } \\
\text { Carskadon } \\
\text { (2005) }\end{array}$ & $\begin{array}{l}\text { School } \\
\text { aged } \\
\text { children } \\
(n=74) \\
\text { Aged } 6 \text { to } \\
12, \text { mean } \\
=10\end{array}$ & Experimental & $\begin{array}{l}\text { Sleep } \\
\text { restriction } \\
\text { and } \\
\text { optimizatio } \\
\text { n, Time in } \\
\text { Bed }\end{array}$ & $\begin{array}{l}\text { Acti- } \\
\text { graphy, } \\
\text { Parent } \\
\text { report }\end{array}$ & $\begin{array}{l}\text { Child outcomes and } \\
\text { sleep habits were } \\
\text { measured across two } \\
\text { experimental } \\
\text { conditions: sleep } \\
\text { optimization (no less } \\
\text { than } 10 \text { hours per } \\
\text { night) and sleep } \\
\text { restriction ( } 8 \text { hours } \\
\text { per night, } 1^{\text {st }} \text { and } 2^{\text {nd }} \\
\text { grade; } 6.5 \text { hours } 3^{\text {rd }} \\
\text { grade and up). } \\
\text { Results showed } \\
\text { significant effects of } \\
\text { experimental } \\
\text { conditions on } \\
\text { academic problems, } \\
\text { school sleepiness, } \\
\text { and attention }\end{array}$ \\
\hline
\end{tabular}




\begin{tabular}{|c|c|c|c|c|c|}
\hline & & & & & $\begin{array}{l}\text { problems at school, } \\
\text { according to teacher } \\
\text { reports. In particular, } \\
\text { the children exhibited } \\
\text { significant more } \\
\text { academic problems } \\
\text { during the restricted } \\
\text { condition, and } \\
\text { marginally more } \\
\text { severe problems with } \\
\text { attention at school. } \\
\text { No effects of age by } \\
\text { condition were } \\
\text { observed. }\end{array}$ \\
\hline $\begin{array}{l}\text { Bates, } \\
\text { Viken, } \\
\text { Alexander, } \\
\text { Beyers, \& } \\
\text { Stockton. } \\
(2002)\end{array}$ & $\begin{array}{l}\text { Preschool } \\
\text { children } \\
(\mathrm{n}=213) \\
\text { attending } \\
\text { Head Start } \\
\text { or } \\
\text { university } \\
\text { pre-k } \\
\text { program; } \\
\text { mean age } \\
=4.9\end{array}$ & $\begin{array}{l}\text { Cross- } \\
\text { sectional }\end{array}$ & $\begin{array}{l}\text { Night sleep } \\
\text { variability, } \\
\text { bedtime } \\
\text { variability, } \\
\text { lateness of } \\
\text { bedtime, } \\
\text { amount of } \\
\text { night sleep, } \\
\text { amount of } \\
\text { total daily } \\
\text { sleep }\end{array}$ & $\begin{array}{l}\text { Parent } \\
\text { daily } \\
\text { diary }\end{array}$ & $\begin{array}{l}\text { Children's night } \\
\text { sleep variability was } \\
\text { significantly related } \\
\text { to teacher ratings of } \\
\text { positive behaviors, } \\
\text { problem behaviors } \\
\text { and daily reports of } \\
\text { positive and negative } \\
\text { behaviors, in } \\
\text { expected directions. } \\
\text { Beditme variability } \\
\text { was significantly } \\
\text { related to ratings of } \\
\text { positive and negative } \\
\text { behaviors and daily } \\
\text { reports of positive } \\
\text { behaviors, and } \\
\text { related to daily } \\
\text { reports of negative } \\
\text { behaviors with } \\
\text { marginal } \\
\text { significance. Poor } \\
\text { school adjustment } \\
\text { was associated with } \\
\text { disrupted sleep, after } \\
\text { controlling for family } \\
\text { stress and } \\
\text { management } \\
\text { practices; the effect } \\
\text { of family-level } \\
\text { predictors on } \\
\text { preschool adjustment } \\
\text { were fully mediated } \\
\text { by child's disrupted } \\
\text { sleep. }\end{array}$ \\
\hline
\end{tabular}




\section{Appendix B}

\section{Results Tables}

Table 2.

Descriptive Statistics for Demographic, Sleep, Self-Regulation and Academic Variables

\begin{tabular}{|c|c|c|c|c|}
\hline & $\mathrm{N}$ & Mean & SD & Range \\
\hline \multicolumn{5}{|l|}{ Demographic } \\
\hline Economic Hardship & 153 & 1.97 & 0.89 & $1-5$ \\
\hline Mobility & 157 & 0.55 & 0.77 & $0-3$ \\
\hline Child/Adult Ratio & 157 & 2.1 & 1.37 & $0.33-8$ \\
\hline Maternal Education & 182 & 2.16 & 0.98 & $1-4$ \\
\hline Pre-K attendance & 182 & 0.9 & 0.31 & $0-1$ \\
\hline Age at baseline (years) & 159 & 5.87 & 0.59 & $4.75-7$ \\
\hline \multicolumn{5}{|l|}{ Sleep } \\
\hline Quantity (hrs) & 158 & 9.79 & 0.76 & $6.65-12$ \\
\hline Latency & 156 & 0.6 & 0.87 & $0-3$ \\
\hline Disruption & 158 & 0.35 & 0.48 & $0-1$ \\
\hline Difficulty Waking & 158 & 1.05 & 1.05 & $0-3$ \\
\hline \multicolumn{5}{|l|}{ Outcomes, T1 } \\
\hline Math & 182 & 419.29 & 20.17 & $361-506$ \\
\hline Literacy & 182 & 379.66 & 42.3 & $283-515$ \\
\hline Self-Regulation & 182 & 22.95 & 19.74 & $0-59$ \\
\hline \multicolumn{5}{|l|}{ Outcomes, T2 } \\
\hline Math & 137 & 439.3 & 17.22 & $396-515$ \\
\hline Literacy & 137 & 423.53 & 37.07 & $344-509$ \\
\hline Self-Regulation & 137 & 32.85 & 19.26 & $0-59$ \\
\hline
\end{tabular}

Note: $n=212$ 
Table 3.

Correlations Between Sleep, Self-Regulation, Math, and Literacy Variables

\begin{tabular}{|c|c|c|c|c|c|c|c|c|c|c|}
\hline & 1. & 2. & 3. & 4. & 5. & 6. & 7. & 8. & 9. & 10. \\
\hline 1. Sleep Quantity & - & & & & & & & & & \\
\hline 2. Sleep Latency & .03 & - & & & & & & & & \\
\hline $\begin{array}{l}\text { 3. Sleep } \\
\text { Disruption }\end{array}$ & .04 & -.06 & - & & & & & & & \\
\hline $\begin{array}{l}\text { 4. Difficulty } \\
\text { Waking }\end{array}$ & $-.17^{*}$ & $.27 * *$ & .04 & - & & & & & & \\
\hline 5. Math, T1 & .06 & -.11 & -.07 & $-.24 * *$ & - & & & & & \\
\hline 6. Literacy, T1 & .06 & -.00 & -.08 & -.11 & $.72 * *$ & - & & & & \\
\hline $\begin{array}{l}\text { 7. Self- } \\
\text { Regulation, T1 }\end{array}$ & -.05 & -.05 & $-.18 *$ & -.15 & $.53 * *$ & $.58 * *$ & - & & & \\
\hline 8. Math, T2 & .04 & .05 & -.09 & -.12 & $.79 * *$ & $.73 * *$ & $.59 * *$ & - & & \\
\hline 9. Literacy, T2 & -.02 & .02 & -.11 & $-.23 *$ & $.61 * *$ & $.78 * *$ & $.54 * *$ & $.73 * *$ & - & \\
\hline $\begin{array}{l}\text { 10. Self- } \\
\text { Regulation, T2 }\end{array}$ & .00 & -.01 & -.03 & -.13 & $.54 * *$ & $.49^{* *}$ & $.60 * *$ & $.60 * *$ & $.52 * *$ & - \\
\hline
\end{tabular}


Table 4.

Multiple Linear Regressions of Self-Regulation and Academic Variables on Sleep Measures and Covariates

\begin{tabular}{|c|c|c|c|c|c|c|c|c|c|}
\hline \multirow[b]{2}{*}{ Predictor } & \multicolumn{3}{|c|}{ Literacy } & \multicolumn{3}{|c|}{ Math } & \multicolumn{3}{|c|}{ Self-Regulation } \\
\hline & $\mathrm{B}$ & SE & $\beta$ & $\mathrm{B}$ & SE & $\beta$ & $\mathrm{B}$ & SE & $\beta$ \\
\hline Intercept & $446.42 * * *$ & 16.05 & 11.25 & $437.30 * * *$ & 7.92 & 24.36 & $31.78 * *$ & 11.44 & 1.29 \\
\hline Baseline & $.63 * * *$ & .08 & .69 & $.63 * * *$ & .06 & .72 & $.52 * * *$ & .08 & .52 \\
\hline \multicolumn{10}{|l|}{$\underline{\text { Covariates }}$} \\
\hline $1^{\text {st }}$ Grade & -9.37 & 5.90 & .12 & $5.57 *$ & 2.29 & .16 & $-6.91 *$ & 2.83 & .18 \\
\hline Boy & -5.00 & 3.80 & -.06 & -.64 & 1.80 & -.02 & -1.42 & 2.74 & -.04 \\
\hline Treatment & 3.01 & 3.85 & .04 & -1.20 & 1.82 & -.03 & 5.03 & 2.76 & .13 \\
\hline $\begin{array}{l}\text { Financial } \\
\text { Hardship }\end{array}$ & 3.52 & 2.55 & .08 & .89 & 1.35 & .04 & 1.01 & 1.78 & .05 \\
\hline Mobility & -4.23 & 2.75 & -.08 & -.88 & 1.41 & -.04 & -.04 & -0.98 & -.00 \\
\hline $\begin{array}{l}\text { Child/Adult } \\
\text { Ratio }\end{array}$ & -1.63 & 1.67 & -.06 & .40 & 0.88 & .03 & -.97 & 1.17 & -.07 \\
\hline Maternal Ed & 1.48 & 2.12 & -.04 & 1.39 & 1.10 & .08 & -.16 & 1.50 & -.01 \\
\hline Pre-K & -10.83 & 8.30 & -.09 & -4.81 & 3.79 & -.08 & -.98 & 5.68 & -.02 \\
\hline \multicolumn{10}{|l|}{$\underline{\text { Sleep }}$} \\
\hline $\begin{array}{l}\text { Quantity } \\
\text { (centered) }\end{array}$ & -2.38 & 2.71 & -.05 & .02 & 1.39 & .00 & .80 & 1.90 & .03 \\
\hline Latency & .78 & 2.52 & .02 & 1.14 & 1.29 & .06 & .14 & 1.82 & .01 \\
\hline Disruption & -3.86 & 4.22 & -.05 & .55 & 2.16 & .02 & .52 & 2.98 & .01 \\
\hline $\begin{array}{l}\text { Difficulty } \\
\text { Waking }\end{array}$ & $-4.30 *$ & 2.21 & -.12 & -.26 & 1.15 & -.02 & -.44 & 1.57 & -.02 \\
\hline
\end{tabular}


Table 5.

Interaction Effects of Grade x Outcomes in Multiple Linear Regressions of Self-Regulation and Academics on Sleep

\begin{tabular}{|c|c|c|c|c|c|c|c|c|c|}
\hline \multirow[b]{2}{*}{ Predictor } & \multicolumn{3}{|c|}{ Literacy } & \multicolumn{3}{|c|}{ Math } & \multicolumn{3}{|c|}{ Self-Regulation } \\
\hline & $\mathrm{B}$ & SE & $\mathrm{p}$ & $\mathrm{B}$ & SE & $\mathrm{p}$ & $\mathrm{B}$ & SE & $\mathrm{p}$ \\
\hline \multicolumn{10}{|l|}{ Sleep Quantity } \\
\hline Intercept & 433.26 & 15.36 & .00 & 438.09 & 7.15 & .00 & 25.57 & 10.59 & .02 \\
\hline Grade*Quantity & -6.03 & 5.54 & .28 & 3.51 & 2.78 & .21 & 1.051 & 4.01 & .79 \\
\hline $\begin{array}{l}\text { Grade (controlling } \\
\text { for interaction) }\end{array}$ & 8.59 & 5.91 & .15 & 5.72 & 2.27 & .01 & 6.967 & 2.84 & .01 \\
\hline $\begin{array}{l}\text { Quantity } \\
\text { (centered) }\end{array}$ & -.32 & 3.30 & .92 & -1.20 & 1.68 & .48 & 0.41 & 2.37 & .86 \\
\hline \multicolumn{10}{|l|}{ Sleep Latency } \\
\hline Intercept & 432.49 & 15.48 & .00 & 437.32 & 7.20 & .00 & 23.71 & 10.50 & .02 \\
\hline Grade*Latency & -2.975 & 4.81 & .54 & -1.97 & 2.48 & .43 & -5.84 & 3.45 & .09 \\
\hline $\begin{array}{l}\text { Grade (controlling } \\
\text { for interaction) }\end{array}$ & 11.03 & 6.54 & .09 & 6.83 & 2.79 & .01 & 10.10 & 3.37 & .00 \\
\hline Latency & 2.35 & 3.58 & .51 & 2.22 & 1.86 & .23 & 3.24 & 2.56 & .21 \\
\hline \multicolumn{10}{|l|}{$\underline{\text { Sleep Disruption }}$} \\
\hline Intercept & 429.43 & 15.64 & .00 & 439.95 & 7.26 & .00 & 25.19 & 10.77 & .02 \\
\hline Grade* Disruption & 10.38 & 8.58 & .23 & -5.93 & 4.28 & .17 & 0.72 & 6.11 & .91 \\
\hline $\begin{array}{l}\text { Grade (controlling } \\
\text { for interaction) }\end{array}$ & 13.43 & 6.78 & .05 & 3.20 & 2.81 & .26 & 7.19 & 3.64 & .05 \\
\hline Disruption & -9.69 & 6.41 & .13 & 3.91 & 3.21 & .22 & 0.14 & 4.59 & .98 \\
\hline \multicolumn{10}{|l|}{$\frac{\text { Difficulty }}{\text { Waking }}$} \\
\hline Intercept & 437.42 & 15.71 & .00 & 438.4 & 7.34 & .00 & 26.74 & 10.77 & .01 \\
\hline $\begin{array}{c}\text { Grade* Difficulty } \\
\text { Waking }\end{array}$ & 5.341 & 4.07 & .19 & .91 & 2.12 & .67 & 2.03 & 2.94 & .49 \\
\hline $\begin{array}{l}\text { Grade (controlling } \\
\text { for interaction) }\end{array}$ & 3.10 & 7.49 & .68 & 4.55 & 3.29 & .17 & 4.57 & 4.33 & .29 \\
\hline Difficulty Waking & -6.65 & 2.81 & .02 & -.66 & 1.47 & .66 & -1.30 & 2.02 & .52 \\
\hline
\end{tabular}


Table 6.

Indirect and Total Effects of Mediation Models

\begin{tabular}{|c|c|c|c|c|c|c|c|c|c|}
\hline \multirow[b]{3}{*}{ Outcome } & \multicolumn{4}{|c|}{ Indirect Effects } & \multicolumn{4}{|c|}{ Total Effects } & \multirow[t]{2}{*}{$\begin{array}{c}\text { Relative } \\
\text { Indirect } \\
\text { Effect }\end{array}$} \\
\hline & \multicolumn{8}{|c|}{ Math Development } & \\
\hline & $B$ & SE & $\beta$ & $p$ & $B$ & SE & $\beta$ & $p$ & \\
\hline $\begin{array}{c}\text { Sleep } \\
\text { Quantity }\end{array}$ & 0.18 & 0.42 & .01 & 0.67 & 0.21 & 1.37 & .01 & 0.88 & .89 \\
\hline $\begin{array}{c}\text { Sleep } \\
\text { Latency }\end{array}$ & 0.02 & 0.40 & .00 & 0.96 & 1.10 & 1.26 & .06 & 0.39 & .02 \\
\hline $\begin{array}{c}\text { Sleep } \\
\text { Disruption }\end{array}$ & 0.12 & 0.66 & .00 & 0.85 & 0.29 & 2.13 & .01 & 0.89 & .38 \\
\hline \multirow[t]{2}{*}{$\begin{array}{l}\text { Difficulty } \\
\text { Waking }\end{array}$} & -0.13 & 0.35 & -.01 & 0.72 & -0.26 & 1.14 & -.02 & 0.83 & .47 \\
\hline & \multicolumn{9}{|c|}{ Literacy Development } \\
\hline $\begin{array}{c}\text { Sleep } \\
\text { Quantity }\end{array}$ & 0.22 & 0.58 & .00 & 0.70 & -2.06 & 2.71 & -.04 & 0.45 & -.10 \\
\hline $\begin{array}{c}\text { Sleep } \\
\text { Latency }\end{array}$ & 0.06 & 0.55 & .00 & 0.91 & 0.89 & 2.52 & .02 & 0.72 & .05 \\
\hline $\begin{array}{c}\text { Sleep } \\
\text { Disruption }\end{array}$ & 0.14 & 0.90 & .00 & 0.88 & -3.37 & 4.22 & -.04 & 0.43 & -.05 \\
\hline $\begin{array}{l}\text { Difficulty } \\
\text { Waking }\end{array}$ & -0.18 & 0.47 & -.01 & 0.71 & -4.17 & 2.22 & -.11 & 0.06 & .04 \\
\hline
\end{tabular}

Note: All mediation models use Self-Regulation at Time 2 (controlling for baseline and covariates) as mediator; Total effects $=$ direct effect + indirect effect; Relative indirect effect $=$ indirect effect/total effect, using standardized measures, rounded to two decimal points. 